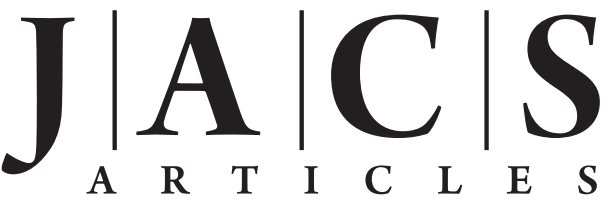

Published on Web 05/14/2010

\title{
Intramolecular Charge Transfer with \\ 1-tert-Butyl-6-cyano-1,2,3,4-tetrahydroquinoline (NTC6) and Other Aminobenzonitriles. A Comparison of Experimental Vapor Phase Spectra and Crystal Structures with Calculations
}

\author{
Sergey I. Druzhinin, ${ }^{* \dagger}$ Peter Mayer, ${ }^{\ddagger}$ Dietmar Stalke, ${ }^{\S}$ Rixa von Bülow, ${ }^{\S}$ \\ Mathias Noltemeyer, ${ }^{\S}$ and Klaas A. Zachariasse ${ }^{*, \dagger}$ \\ Max-Planck-Institut für biophysikalische Chemie, Spektroskopie und Photochemische Kinetik, \\ 37070 Göttingen, Germany, Department Chemie und Biochemie, \\ Ludwig-Maximilians-Universität, Butenandtstrasse 5-13, Haus F, 81377 München, Germany, and \\ Institut für Anorganische Chemie, Universität Göttingen, Tammannstrasse 2, \\ 37077 Göttingen, Germany
}

Received February 15, 2010; E-mail: sdruzhi@gwdg.de; kzachar@gwdg.de

\begin{abstract}
Calculations of molecular structures in the electronic ground state $\mathrm{S}_{0}$ and of excited state and fluorescence energies generally refer to the gas phase. This complicates a comparison with experimental data, which often are only available for molecules in solution. Therefore, experimental absorption and fluorescence spectra in the vapor phase are presented for 1-tert-butyl-6-cyano-1,2,3,4-tetrahydroquinoline (NTC6), 1-methyl-6-cyano-1,2,3,4-tetrahydroquinoline (NMC6), 4-(dimethylamino)benzonitrile (DMABN), and 4-(diisopropylamino)benzonitrile (DIABN). NTC6 and DIABN show a dual fluorescence in the gas phase, with emissions from an intramolecular charge transfer (ICT) and a locally excited (LE) state, whereas with NMC6 and DMABN only LE emission is observed. For a comparison of the experimental molecular structure in $\mathrm{S}_{0}$ with the results of recent computations, X-ray crystal structures of NTC6, NMC6, and several analogues are presented. For DMABN, NMC6, and NTC6, LE/ICT energy diagrams are constructed, in which the experimental energies of the Franck-Condon singlet excited states $\mathrm{S}_{1}$ and $\mathrm{S}_{2}$, and the LE and ICT states together with their emissions, are compared with the calculations. The LE and ICT dipole moments are also discussed. This comparison reveals substantial differences, in particular for the ICT energies, but even for the structure of the $S_{0}$ ground states. It is concluded that the computed ICT states of NTC6 and DMABN, in which the full conjugation of the phenyl ring is interrupted, is different from the ICT states measured in the experiments.
\end{abstract}

\section{Introduction}

With the rigidified aminobenzonitrile derivative 1-tert-butyl6-cyano-1,2,3,4-tetrahydroquinoline (NTC6) fast and efficient intramolecular charge transfer (ICT) in the singlet excited state has been observed in a series of solvents, from the nonpolar alkanes to the polar solvents acetonitrile $(\mathrm{MeCN})$ and methanol. ${ }^{1,2}$ For the ICT state of NTC6, a dipole moment $\mu_{\mathrm{e}}$ (ICT) of $19 \mathrm{D}$ has been reported, similar to that of 4-(dimethylamino)benzonitrile (DMABN) (17 D) and 4-(diisopropylamino)benzonitrile $(\mathrm{DIABN})(18 \mathrm{D}) .{ }^{1,3} \mathrm{ICT}$ reaction times of $2.2 \mathrm{ps}$ in $n$-hexane and $0.82 \mathrm{ps}$ in $\mathrm{MeCN}$ have been determined for NTC6 from femtosecond excited-state absorption (ESA) spectra at $22{ }^{\circ} \mathrm{C}$. Such an ICT reaction does not occur for the other 1-alkyl-6cyano-1,2,3,4-tetrahydroquinolines NIC6 ${ }^{1,2}$ (isopropyl), NEC6 ${ }^{1}$

\footnotetext{
† Max-Planck-Institut für biophysikalische Chemie.

Ludwig-Maximilians-Universität.

\& Universität Göttingen.

(1) Zachariasse, K. A.; Druzhinin, S. I.; Bosch, W.; Machinek, R. J. Am. Chem. Soc. 2004, 126, 1705 .

(2) Druzhinin, S. I.; Kovalenko, S. A.; Senyushkina, T.; Zachariasse, K. A J. Phys. Chem. A 2007, 111, 12878.

(3) Schuddeboom, W.; Jonker, S. A.; Warman, J. M.; Leinhos, U.; Kühnle, W.; Zachariasse, K. A. J. Phys. Chem. 1992, 96, 10809.
}

(ethyl) and $\mathrm{NMC}^{1-5}$ (methyl). The small energy gap $\Delta E\left(\mathrm{~S}_{1}, \mathrm{~S}_{2}\right)$ between the two lowest-excited singlet states of NTC6 as compared with NIC6, NEC6, and NMC6, is taken to be the main reason for the appearance of ICT with NTC6, as well as for its absence with the three other tetrahydroquinolines. ${ }^{1,2}$

The observations with NTC6 are considered to support the planar ICT (PICT) model. ${ }^{1,2,6-9}$ In this model, the main requirement for the occurrence of ICT in aminobenzonitriles and other electron donor(D)/acceptor(A) molecules is the presence of a relatively small gap $\Delta E\left(\mathrm{~S}_{1}, \mathrm{~S}_{2}\right)$. Although it is stated in the PICT model that a perpendicular D/A twist is not

(4) Visser, R. J.; Varma, C. A. G. O. J. Chem. Soc., Faraday Trans. 2 1980, 76, 453.

(5) Leinhos, U.; Kühnle, W.; Zachariasse, K. A. J. Phys. Chem. 1991, 95, 2013.

(6) Zachariasse, K. A.; Grobys, M.; von der Haar, Th.; Hebecker, A.; Il'ichev, Yu. V.; Morawski, O.; Rückert, I.; Kühnle, W. J. Photochem. Photobiol., A 1997, 105, 373.

(7) Zachariasse, K. A. Chem. Phys. Lett. 2000, 320, 8.

(8) Il'ichev, Yu. V.; Kühnle, W.; Zachariasse, K. A. J. Phys. Chem. A 1998, $102,5670$.

(9) Zachariasse, K. A.; Grobys, M.; von der Haar, Th.; Hebecker, A.; Il'ichev, Yu. V.; Jiang, Y.-B.; Morawski, O.; Kühnle, W. J. Photochem. Photobiol., A 1996, 102, 59. Erratum: J. Photochem. Photobiol., A 1998, 115, 259. 
required for ICT (contrary to what is postulated for the twisted ICT (TICT) model), ${ }^{10,11}$ it is not essential that the amino and benzonitrile moieties are completely coplanar. A sufficiently large electronic coupling between the D and A groups, which can be achieved at a substantial (but not perpendicular) aminophenyl twist angle $\theta$, is hence more important than a strict planarity. ${ }^{2}$ It should be noted in this connection that the PICT model does not make a statement on the presence of a quinoidal character for the ICT state. ${ }^{12}$

Picosecond fluorescence decays and femtosecond ESA spectra do not provide direct information on the molecular structure of the LE and ICT reactants. Experimental access to the ICT structure of aminobenzonitriles has only been obtained from picosecond X-ray experiments with crystalline DIABN, leading to the conclusion that the ICT state is effectively planar $(\theta=$ $\left.10^{\circ}\right) .{ }^{13}$ Other more detailed structural properties, such as bond lengths and angles, could not be determined, however. Elsaesser et al. have expressed doubt on the interpretation of the timeresolved X-ray data presented in refs 13 and 14. In their experiments with crystalline DIABN, it is claimed that the ICT state was prepared directly by $400 \mathrm{~nm}$ laser excitation and not by two-photon absorption. Note that the energy of this excitation light is around $6000 \mathrm{~cm}^{-1}$ below that of the $S_{1}$ state of DIABN in the crystal. ${ }^{15}$

Further direct experimental information on the structure of the ICT state of D/A molecules came from the rigidified compounds NTC6, $^{1,2}$ fluorazene $^{16}$ (FPP), 4-fluorofluorazene ${ }^{17}$ (FPP4F), and 4-cyanofluorazene ${ }^{18}$ (FPP4C). As an efficient and fast ICT reaction takes place with these substances, it was concluded that a full perpendicular amino twist (i.e., to a TICT state) is not a necessary requirement for the occurrence of an ICT reaction in aminobenzonitriles and related D/A systems. ${ }^{1,2,16-18}$ The reasoning was that such TICT states, requiring a large amplitude motion with a high energy barrier, would be inaccessible in the rigidified molecules NTC6, FPP, FPP4F, and FPP4C during the few picoseconds in which the ICT reaction was found to take place.

In recent years, publications have appeared with calculations of the energies and dipole moments for the electronic ground state $\mathrm{S}_{0}$ and the various accessible excited states such as LE (locally excited), TICT and PICT of NTC6 and NMC6, in a comparison with DMABN. ${ }^{19-23}$ Amatatsu $^{19}$ employed the

(10) Grabowski, Z. R.; Rotkiewicz, K.; Rettig, W. Chem. Rev. 2003, 103, 3899.

(11) Rotkiewicz, K.; Grabowski, Z. R.; Krǒwczyński, A.; Kühnle, W. J. Lumin. 1976, 12/13, 877.

(12) Galievsky, V. A.; Zachariasse, K. A. Acta Phys. Pol., A 2007, 112, S-39.

(13) Techert, S.; Zachariasse, K. A. J. Am. Chem. Soc. 2004, 126, 5593.

(14) Braun, M.; v. Korff-Schmising, C.; Kiel, M.; Zhavoronkov, N.; Dreyer, J.; Bargheer, M.; Elsaesser, T.; Root, C.; Schrader, T. E.; Gilch, P.; Zinth, W.; Woerner, M. Phvs. Rev. Lett. 2007, 98, 248301.

(15) Druzhinin, S. I.; Demeter, A.; Zachariasse, K. A. Chem. Phvs. Lett. 2001, 347, 421.

(16) (a) Yoshihara, T.; Druzhinin, S. I.; Zachariasse, K. A. J. Am. Chem. Soc. 2004, 126, 8535. (b) Druzhinin, S. I.; Kovalenko, S. A.; Senyushkina, T. A.; Demeter, A.; Zachariasse, K. A. J. Phys. Chem. A 2010, 114, 1621.

(17) Druzhinin, S. I.; Kovalenko, S. A.; Senyushkina, T. A.; Demeter, A.; Januskevicius, R.; Mayer, P.; Stalke, D.; Machinek, R.; Zachariasse, K. A. J. Phys. Chem. A 2009, 113, 9304.

(18) Druzhinin, S. I.; Kovalenko, S. A.; Senyushkina, T. A.; Demeter, A.; Machinek, R.; Noltemeyer, M.; Zachariasse, K. A. J. Phys. Chem. A 2008, 112, 8238. Erratum, J. Phvs. Chem. A 2009, 113, 520.

(19) Amatatsu, Y. J. Phys. Chem. A 2005, 109, 7225.

(20) Gómez, I.; Mercier, Y.; Reguero, M. J. Phvs. Chem. A 2006, 110, 11455.
Chart 1. Molecular structures and Atom Numbering for 1-tert-Butyl-6-cyano-1,2,3,4-tetrahydroquinoline (NTC6), 1-Isopropyl-5-cyanoindoline (NIC5),

3,5-Dimethyl-4-(dimethylamino)benzonitrile (MMD),

4-(Diisopropylamino)benzonitrile (DIABN), and

4-(Dimethylamino)benzonitrile (DMABN)

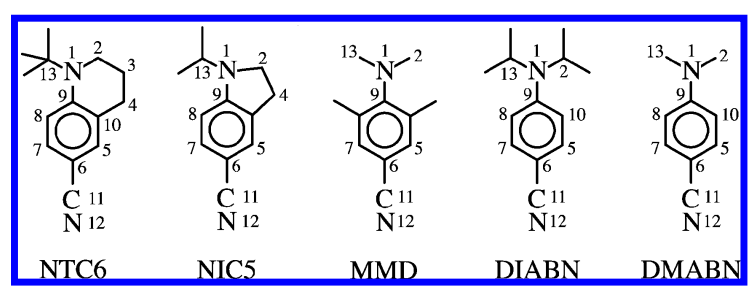

The numbering of the atoms in MMD, DIABN, and DMABN has been chosen to match that of NTC6 and NIC5.

CASSCF and MRMP2 methods and, in combination with the polarized continuum model (PCM), also obtained energies for DMABN in nonpolar (alkane) solvents. Reguero ${ }^{20,21}$ and Hättig $^{22,23}$ did not take such a solvent influence into account; their results, hence, refer exclusively to the gas phase. In ref 20, CASSCF was likewise employed, combined with CASPT2. The calculations in ref 22 were carried out with the approximate coupled-cluster singles-and-doubles model CC2. Dynamic electron correlation (dec) was incorporated in ref 19. It was found that inclusion of dec leads to (from a photophysical point of view), extremely large stabilizations of the LE (around $1 \mathrm{eV}$ ) and in particular of the ICT (around $2 \mathrm{eV}$ ) states. A similar stabilizing effect of dec was found for the CASPT2 method in ref 20 . In the CC2 model, ${ }^{22}$ dec is not discussed explicitly. Incorporation of dec tends to preferentially stabilize TICT as compared with PICT structures, as the perpendicular amino twist limits the effective area of the molecule available for the delocalization of the electrons. ${ }^{24}$ The claim made in refs 19 and 20 that the stabilization of CASPT2 relative to CASSCF (different for the LE and ICT states) has no effect on the overall 'topology' 20 of the potential energy surfaces of these states is surprising, in view of the fact that ICT states located clearly above $S_{1}(L E)$ obviously do not play a role in the ICT photophysics as such.

In the present article, absorption and fluorescence spectra of NTC6 and NMC6 in the vapor phase are presented. For comparison, the gas phase spectra of DMABN and DIABN are also shown. ${ }^{25,26}$ The emission spectra of NTC6 and DIABN consist of a dual fluorescence from a LE and an ICT state, showing that these molecules undergo an ICT reaction in the vapor phase. This is not the case for NMC6 and DMABN, for which only a single LE fluorescence band is observed. The experimental energetics of the LE and ICT states derived from these spectra will be used in a comparison with the computational results from refs 19-23. In addition, the molecular structure data determined from X-ray crystal analysis of NTC6, NMC6, and a number of related molecules (Chart 1) will be

(21) Gómez, I.; Reguero, M.; Boggio-Pasqua, M.; Robb, M. A. $\underline{\text { J. Am. }}$ Chem. Soc. 2005, 127, 7119.

(22) Hättig, C.; Hellweg, A.; Köhn, A. J. Am. Chem. Soc. 2006, 128, 15672.

(23) Köhn, A.; Hättig, C. J. Am. Chem. Soc. 2004, 126, 7399.

(24) Borden, W. T.; Davidson, E. R. Acc. Chem. Res. 1996, $29,67$.

(25) Daum, R.; Druzhinin, S.; Ernst, D.; Rupp, L.; Schroeder, J.; Zachariasse, K. A. Chem. Phys. Lett. 2001, 341, 272.

(26) Zachariasse, K. A.; Grobys, M.; Tauer, E. Chem. Phvs. Lett. 1997, $274,372$. 
compared with the calculated ${ }^{19-23}$ bond lengths and angles of NTC6 and NMC6 in the ground state.

\section{Experimental Section}

The synthesis of the molecules NXC6 (NTC6, NIC6, NEC6, NMC6), the 1-alkyl-5-cyanoindolines NXC5 (NIC5, NEC5 (ethyl), NMC5 (methyl)), DIABN, DMABN, and MMD has been reported previously. ${ }^{1,27,28}$ HPLC was the last step in the purification of these molecules. For the measurement of the vapor phase absorption and fluorescence spectra of NTC6, NMC6, DIABN and DMABN, the samples were contained in a sealed quartz cuvette of $1 \mathrm{~cm}$ path length. Care was taken to maintain the optical surfaces of the cuvette at a higher temperature than that of its tip. The temperatures were controlled by a JUMO Dicon 1000 Universal Profile Controller. The vapor pressure of the compounds was adjusted by varying the temperature. The measurement of the absorption and fluorescence spectra was described earlier. ${ }^{29}$ The X-ray crystal structures were solved by direct methods with SIR $97^{30}$ and refined by full-matrix least-squares calculations ${ }^{31}$ on $F^{2}$ with SHELXL-97.

\section{Results and Discussion}

Absorption and Fluorescence Spectra in the Vapor Phase. To be able to make a direct comparison of the outcome of calculations ${ }^{19-23}$ for NTC6, NMC6, and DMABN with experimental results for these molecules in the excited singlet state, their absorption and fluorescence spectra were measured in the vapor phase, as the computations refer to the gas phase at $0 \mathrm{~K}$. In this manner, complications due to the theoretical incorporation $^{19}$ of solvent effects are avoided. It is clear from a comparison of the fluorescence spectra of DMABN, DIABN, NMC6, and NTC6 in the vapor phase (Figures 1 and 2) that with DIABN ${ }^{25}$ and NTC6 an additional ICT emission band appears, red-shifted with respect to the LE emission (Figures $1 \mathrm{~b}$ and $2 \mathrm{~b}$ ). This means that an ICT reaction takes place with DIABN and NTC6 in the vapor phase, whereas for DMABN ${ }^{25,32}$ and NMC6 $^{32}$ such an ICT emission is absent and hence experimental evidence for an LE $\rightarrow$ ICT reaction of these molecules is not found, contrary to an earlier suggestion, that ICT emission should be observed from gas phase DMABN if excited within the $\mathrm{L}_{\mathrm{a}}$ band. ${ }^{32 \mathrm{~b}}$

DMABN and DIABN Vapor. Absorption Spectra. The absorption spectrum of DMABN in the vapor phase (Figure 1a) consists of a main band with a maximum $\tilde{\nu}^{\max }($ abs) at 36830 $\mathrm{cm}^{-1}$ and a weak slightly structured absorption with a lowestenergy shoulder at $32210 \mathrm{~cm}^{-1}$ (Table 1). These bands have been attributed to $S_{2}\left(L_{a}, C T\right)$ and $S_{1}\left(L_{b}\right),{ }^{26}$ respectively, giving an energy difference $\tilde{v}^{\max }\left(\mathrm{S}_{2}, \mathrm{abs}\right)-\tilde{v}\left(\mathrm{~S}_{1}{ }^{0}, \mathrm{abs}\right)$ of $4620 \mathrm{~cm}^{-1}$ between the two lowest excited singlet states. ${ }^{33}$ The energy $\tilde{v}\left(\mathrm{~S}_{1}{ }^{0}, \mathrm{abs}\right)$ in the vapor phase is approximately the same as the value of $32246.5 \mathrm{~cm}^{-1}$ obtained from jet spectra. ${ }^{25}$ With DMABN in $n$-hexane, the energy gap $\tilde{v}^{\max }\left(\mathrm{S}_{2}, \mathrm{abs}\right)-\tilde{v}\left(\mathrm{~S}_{1}{ }^{0}, \mathrm{abs}\right)$

(27) Demeter, A.; Druzhinin, S.; George, M.; Haselbach, E.; Roulin, J.-L.; Zachariasse, K. A. Chem. Phvs. Lett. 2000, 323, 351.

(28) Demeter, A.; Zachariasse, K. A. Chem. Phvs. Lett. 2003, 380, 699.

(29) Druzhinin, S. I.; Ernsting, N. P.; Kovalenko, S. A.; Lustres, L. P.; Senyushkina, T. A.; Zachariasse, K. A. J. Phvs. Chem. A 2006, 110, 2955.

(30) Altomare, A.; Burla, M. C.; Camalli, M.; Cascarano, G. L.; Giacovazzo, C.; Guagliardi, A.; Moliterni, A. G. G.; Polidori, G.; Spagna, R. J. Appl. Crvstallogr. 1999, 32, 115.

(31) Sheldrick, G. M. SHELXS-97 and SHELXL-97, Programs for the Solution and Refinement of Crystal Structures; Universität Göttingen: Göttingen, 1997.

(32) (a) Fuss, W.; Schmid, W. E.; Pushpa, K. K.; Trushin, S. A.; Yatsuhashi, T. Phys. Chem. Chem. Phys. 2007, 9, 1151. (b) Fuss, W.; Pushpa, K. K.; Rettig, W.; Schmid, W. E.; Trushin, S. A. Photochem. Photobiol. Sci. 2002, 1, 255.

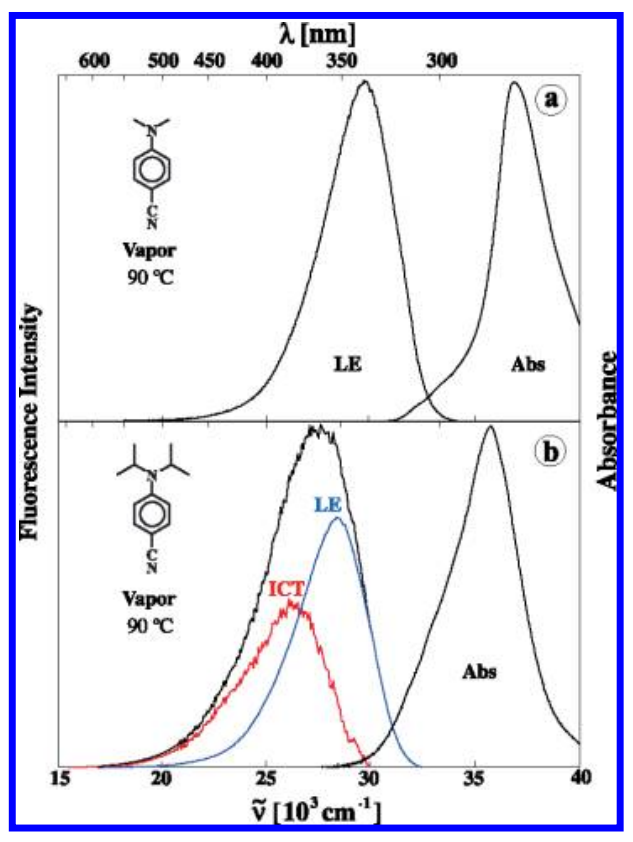

Figure 1. Absorption and fluorescence spectra of (a) DMABN and (b) DIABN in the vapor phase at $90{ }^{\circ} \mathrm{C}$. The overall fluorescence spectrum of DIABN has been separated into the emissions from the locally excited (LE) and intramolecular charge transfer (ICT) states by adopting the fluorescence spectrum of DMABN as that of the LE state of DIABN. Excitation wavelength: $280 \mathrm{~nm}$.

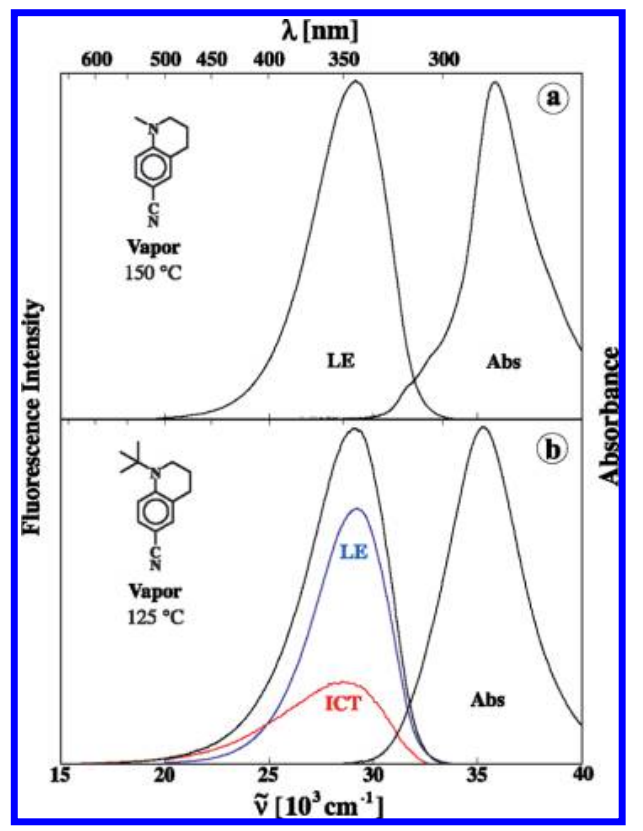

Figure 2. Absorption and fluorescence spectra in the vapor phase of (a) NMC6 at $150{ }^{\circ} \mathrm{C}$ and (b) NTC6 at $125{ }^{\circ} \mathrm{C}$. The overall fluorescence spectrum of NTC6 has been separated into the contributions of the locally excited (LE) and intramolecular charge transfer (ICT) states by adopting the fluorescence spectrum of NMC6 as that of the LE state of NTC6. Excitation wavelength: $274 \mathrm{~nm}$ for NMC6 and $284 \mathrm{~nm}$ for NTC6.

is considerably smaller $\left(3820 \mathrm{~cm}^{-1}\right),{ }^{26,33}$ a difference caused by the preferential solvent stabilization of the $S_{2}$ state due to its more pronounced polar character. ${ }^{34,35}$

In the gas phase absorption spectrum of DIABN (Figure 1b), $\tilde{v}^{\max }\left(\mathrm{S}_{2}, \mathrm{abs}\right)=35700 \mathrm{~cm}^{-1}$, whereas the $\mathrm{S}_{1}$ band is fully covered by the $\mathrm{S}_{2}$ absorption. From jet spectra, ${ }^{25} \tilde{v}\left(\mathrm{~S}_{1}{ }^{0}, \mathrm{abs}\right)=31751.8$ $\mathrm{cm}^{-1}$ can nevertheless be determined (Table 1). The gap 
Table 1. Absorption Data $\tilde{v}^{\max }\left(\mathrm{S}_{2}, \mathrm{abs}\right), \tilde{v}^{\max }\left(\mathrm{S}_{1}, \mathrm{abs}\right)$, and $\tilde{v}\left(\mathrm{~S}_{1}{ }^{0}, \mathrm{abs}\right)$, Emission Maxima $\tilde{v}^{\max }(\mathrm{LE})$ and $\tilde{v}^{\max }(\mathrm{ICT})$, and ICT/LE Fluorescence Quantum Yield Ratio $\Phi^{\prime}(I C T) / \Phi($ LE) of DMABN, DIABN, NMC6, and NTC6 in the Vapor Phase (Figures 1 and 2)

\begin{tabular}{lcccccccc}
\hline & $\tilde{v}^{\max }\left(\mathrm{S}_{2}, \mathrm{abs}\right)^{a}\left[\mathrm{~cm}^{-1}\right]$ & $\tilde{v}\left(\mathrm{~S}_{1}{ }^{0}, \mathrm{abs}\right)^{b}\left[\mathrm{~cm}^{-1}\right]$ & $\tilde{\nu}\left(\mathrm{S}_{1}{ }^{0}, \mathrm{abs}\right)^{c}\left[\mathrm{~cm}^{-1}\right]$ & $\tilde{v}^{\max }\left(\mathrm{S}_{1}, \mathrm{abs}\right)^{d}\left[\mathrm{~cm}^{-1}\right]$ & $\Delta E\left(\mathrm{~S}_{1}, \mathrm{~S}_{2}\right)^{e}\left[\mathrm{~cm}^{-1}\right]$ & $\tilde{v}^{\max }(\mathrm{LE})\left[\mathrm{cm}^{-1}\right]$ & $\tilde{v}^{\max }(\mathrm{ICT})\left[\mathrm{cm}{ }^{-1}\right]$ & $\Phi^{\prime}(\mathrm{ICT}) / \Phi(\mathrm{LE})$ \\
\hline DMABN & 36830 & 32246.5 & 32210 & 33310 & 3520 & 29670 & $(28630)^{f}$ & 0 \\
DIABN & 35700 & 31751.8 & & $32850^{g}$ & 2850 & 28360 & 26270 \\
NMC6 & 35850 & & 31770 & 32870 & 2980 & 29140 & 0.74 \\
NTC6 & 35240 & & $(31770)^{h}$ & 32870 & 2370 & 29180 & 28560
\end{tabular}

\footnotetext{
${ }^{a}$ Main $\left(\mathrm{S}_{2}\right)$ vapor phase absorption maximum. ${ }^{b} 0-0$ transition in jet spectrum. ${ }^{25}{ }^{c}$ Lowest vibrational peak in vapor phase absorption spectrum. ${ }^{d} \tilde{v}\left(\mathrm{~S}_{1}{ }^{0}\right.$,abs,vapor $)+1100 \mathrm{~cm}^{-1}$, see text. ${ }^{e} \Delta E\left(\mathrm{~S}_{1}, \mathrm{~S}_{2}\right)=\tilde{v}^{\max }\left(\mathrm{S}_{2}\right.$, abs $)-\tilde{v}^{\max }\left(\mathrm{S}_{1}\right.$, abs $) .{ }^{f}$ Extrapolated from solvent series, see Figure 7 , Table 3 and text, below. With DMABN in the gas phase ICT fluorescence is not observed (Figure 1a). ${ }^{g}$ From $\tilde{v}\left(\mathrm{~S}_{1}{ }^{0}\right.$,abs,jet). ${ }^{h}$ Extrapolated value, based on the similarity of the onset of the absorption spectra of NMC6 and NTC6 in the vapor phase, see text.
}

$\tilde{v}^{\max }\left(\mathrm{S}_{2}, \mathrm{abs}\right)-\tilde{v}\left(\mathrm{~S}_{1}{ }^{0}, \mathrm{abs}\right)$ of $3950 \mathrm{~cm}^{-1}$ is clearly smaller than for DMABN $\left(4620 \mathrm{~cm}^{-1}\right)$, similar to what has been observed ${ }^{27}$ in $n$-hexane.

Fluorescence Spectra. The vapor phase fluorescence spectrum of DMABN (Figure 1a) consists of a single band, attributed to the LE state. ${ }^{25}$ In contrast to that, dual emission from a LE as well as from an ICT state is found in the fluorescence spectrum of the DIABN vapor (Figure 1b). The ICT/LE quantum yield ratio $\Phi^{\prime}(\mathrm{ICT}) / \Phi(\mathrm{LE})$ of this dual emission is equal to 0.74 (Table 1).

NMC6 and NTC6 Vapor. Absorption Spectra. The absorption spectrum of NMC6 in the vapor phase (Figure 2a) is similar to that of DMABN, with a maximum $\tilde{v}^{\max }\left(\mathrm{S}_{2}, \mathrm{abs}\right)$ at $35850 \mathrm{~cm}^{-1}$, a well-separated weak structured absorption with the lowestenergy shoulder $\tilde{v}\left(\mathrm{~S}_{1}{ }^{0}, \mathrm{abs}\right)$ at $31770 \mathrm{~cm}^{-1}$ (Table 1) resulting in a relatively large energy difference $\tilde{v}^{\max }\left(\mathrm{S}_{2}, \mathrm{abs}\right)-\tilde{v}\left(\mathrm{~S}_{1}{ }^{0}, \mathrm{abs}\right)$ of $4080 \mathrm{~cm}^{-1}$.

For NTC6 in the vapor phase (Figure 2b), the broad $\mathrm{S}_{2}$ absorption band strongly overlaps with $\mathrm{S}_{1}$, a clear indication that $\Delta E\left(\mathrm{~S}_{1}, \mathrm{~S}_{2}\right)^{33}$ of NTC6 is considerably smaller than that of NMC6, see Table 1. As the same onset is observed for the absorption spectra of NMC6 and NTC6 in the vapor phase (Figure 2), the $\tilde{v}\left(\mathrm{~S}_{1}{ }^{0}, \mathrm{abs}\right)$ of NMC6 and NTC6 are taken to have the same value of $31770 \mathrm{~cm}^{-1}$ (Table 1). This leads to an energy difference $\tilde{v}^{\max }\left(\mathrm{S}_{2}, \mathrm{abs}\right)-\tilde{v}\left(\mathrm{~S}_{1}{ }^{0}, \mathrm{abs}\right)$ of $3470 \mathrm{~cm}^{-1}$ for NTC6.

Fluorescence Spectra. The fluorescence spectrum of NMC6 in the vapor phase (Figure $2 \mathrm{a}$ ) consists of a single LE emission band, similar to what was seen for DMABN in Figure 1a. The gas phase emission spectrum of NTC6 (Figure 2b), however, contains two bands, a dual fluorescence from an LE and an ICT state. The ratio $\Phi^{\prime}(\mathrm{ICT}) / \Phi(\mathrm{LE})$ for NTC6 is with 0.44 somewhat smaller than that of DIABN $(0.74$, Figure $1 \mathrm{~b}$, Table 1$)$, indicating that $-\Delta H$ for NTC6 in the gas phase is relatively small $\left(-\Delta H=2.4 \mathrm{~kJ} / \mathrm{mol}\right.$ in $n$-hexane, with $\Phi^{\prime}(\mathrm{ICT}) / \Phi(\mathrm{LE})$ $=0.31$ at $65{ }^{\circ} \mathrm{C}$ and 0.26 at $150{ }^{\circ} \mathrm{C}$ (extrapolated), from ref 2 , see below). These results for DIABN and NTC6 show that an ICT reaction can indeed occur in the vapor phase, without solvent molecules being involved.

Gas Phase ICT Emission Maxima. Solvatochromic Plot for NTC6 vs DIABN. The vapor phase ICT emission maxima of NTC6 and DIABN (Table S1 in Supporting Information) are employed to make a plot of the $\tilde{v}^{\max }$ (ICT) of NTC6 vs those of DIABN (Figure 3). This plot contains data for a series of solvents at $25{ }^{\circ} \mathrm{C}$ including perfluoromethylcyclohexane $(\mathrm{pFMCH})$, which has properties intermediate $\mathrm{e}^{25,36,37}$ between those of an alkane solvent and the gas phase. ${ }^{1}$ The vapor phase maxima (and those of $\mathrm{pFMCH}$ ) are on the same line as the solvent data, supporting our conclusion that the red-shifted new emission bands of NTC6 and DIABN in the gas phase (Figures $2 \mathrm{a}$ and 1a) indeed originate from an ICT state.

From the plot of $\tilde{v}^{\max }(\mathrm{ICT}, \mathrm{NTC6})$ vs $\tilde{v}^{\max }(\mathrm{ICT}, \mathrm{DIABN})$ in Figure 3 , an ICT dipole moment $\mu_{\mathrm{e}}(\mathrm{ICT})=18.0 \mathrm{D}$ is determined

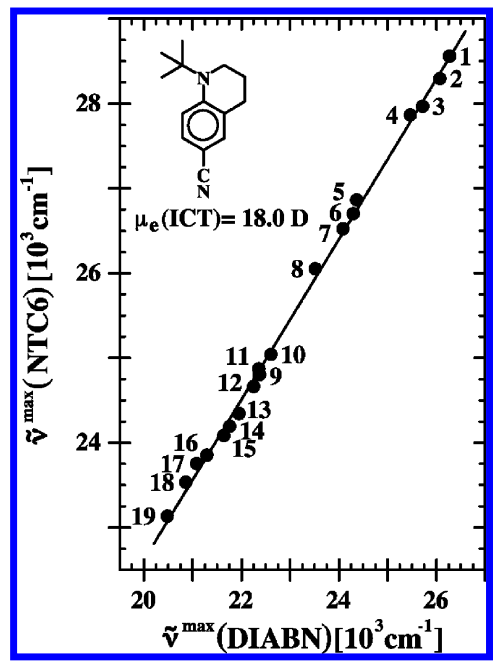

Figure 3. Plot of the ICT fluorescence maxima $\tilde{v}^{\max }$ (ICT) of NTC6 versus those of DIABN in the vapor phase and a series of solvents spanning the polarity scale. The solution data are for $25^{\circ} \mathrm{C}$, whereas the vapor phase maxima are for $90{ }^{\circ} \mathrm{C}$ (DIABN) and $125^{\circ} \mathrm{C}$ (NTC6), see Figures 1 and 2 and Table $\mathrm{S} 1$ in Supporting Information. The numbering of the media is as follows: 1. vapor phase; 2. perfluoromethylcyclohexane; 3. $n$-hexane; 4. $n$-hexadecane; 5 . di(n-pentyl) ether; 6 . di (n-butyl) ether; 7. di(n-propyl) ether; 8. diethyl ether; 9. tetrahydrofuran; $10 . n$-butyl acetate; $11 . n$-propyl acetate; 12. ethyl acetate; 13. methyl acetate; 14. dichloromethane; 15. 1,2dichloroethane; 16 . $n$-butyl cyanide; 17 . $n$-propyl cyanide; 18 . ethyl cyanide; 19. acetonitrile $(\mathrm{MeCN})$. From the slope of the plot, an ICT dipole moment $\mu_{\mathrm{e}}(\mathrm{ICT})=18.0 \mathrm{D}$ is determined for NTC6, based on $\mu_{\mathrm{e}}(\mathrm{ICT})=18 \mathrm{D}$ for DIABN, see text and eqs $1-3$. A list of DIABN maxima, together with those of NTC6, can be found in Supporting Information (Table S1).

for NTC6, based on $\mu_{\mathrm{e}}(\mathrm{ICT})=18 \mathrm{D}$ for DIABN. ${ }^{27} \mathrm{~A}$ similar plot, not including the vapor phase and the nonpolar solvents pFMCH, $n$-hexane and $n$-hexadecane resulted in a somewhat larger dipole moment $\mu_{\mathrm{e}}(\mathrm{ICT})=19.2 \mathrm{D}$ for NTC6. ${ }^{1}$ A plot of $\tilde{v}^{\max }$ (ICT) of NTC6 in a series of solvents from di-( $n$-hexyl) ether to $\mathrm{MeCN}$ against the solvent polarity parameter $g(\varepsilon, n)=$ $f(\varepsilon)-1 / 2 f\left(n^{2}\right)$, see eqs $1-3$, gave $\mu_{\mathrm{e}}(\mathrm{ICT})=17.6 \mathrm{D}{ }^{1}$

$$
\begin{gathered}
\tilde{v}^{\max }(\mathrm{flu})=-\frac{1}{2 h c \rho^{3}} \mu_{e}\left(\mu_{e}-\mu_{g}\right) g(\varepsilon, n)+\text { const } \\
f(\varepsilon)=\frac{\varepsilon-1}{2 \varepsilon+1} \\
f\left(n^{2}\right)=\frac{n^{2}-1}{2 n^{2}+1}
\end{gathered}
$$

In eqs $1-3, \mu_{\mathrm{e}}$ and $\mu_{\mathrm{g}}$ are respectively the excited-state and ground-state dipole moment, $\varepsilon$ and $n$ are respectively the dielectric constant and the refractive index of the solvent, and $\rho$ is the Onsager radius of the solute. ${ }^{1,37}$ 
Crystal Structure of NTC6, NIC6, and Other Aminobenzonitriles. In order to compare the experimental molecular structure of NTC6, NMC6, and DMABN in the electronic ground state with the outcome of calculations, ${ }^{19-23}$ the results of an X-ray crystal analysis of these molecules are employed. The experimental bond lengths, bond angles, amino twist angle $\theta$ and pyramidal angle $\varphi$ are collected in Table 2. Structure data of the 1-alkyl-6-cyano-1,2,3,4-tetrahydroquinolines NIC6, NEC6, and NMC6, the 1-alkyl-5-cyanoindolines NIC5, NEC5, and NMC5, as well as the 4-aminobenzonitriles DIABN and 3,5dimethyl-4-(dimethylamino)benzonitrile(MMD) are also listed..$^{38,39}$

The molecular structures of NTC6 and NIC6 are depicted in Figure 4. The structural differences between these molecules and also those with NEC6 and NMC6 (Table 2), mainly involve the amino twist angle $\theta$, the pyramidal angle $\varphi$ and the $\mathrm{N}(1)-\mathrm{C}(13)$ bond length between the amino nitrogen and the connecting $\mathrm{C}(13)$ atom of the alkyl substituent (Chart 1). The $\mathrm{N}(1)-\mathrm{C}(9)$ bond length for the NXC6 and NXC5 (Table 2) is seen to be kept more or less constant by the presence of the alicyclic ring, i.e., it practically does not depend on $\theta$, in contrast to what is found for the series DMABN, DIABN and MMD.

Experimental and Calculated Ground-State Structure Parameters of NXC6 and NXC5. In this section, a comparison between experimental and computed structure parameters of NXC6, NXC5 and a number of related molecules (Table 2) is made: amino twist and pyramidality, bond lengths and angles, and also the phenyl ring quinoidality.

Amino Twist Angle $\boldsymbol{\theta}$. The experimental amino twist angle $\theta$ is small for NMC6 $\left(3.3^{\circ}\right)$ and NEC6 $\left(4.6^{\circ}\right)$ and then becomes larger for NIC6 $\left(9.5^{\circ}\right)$ and NTC6 $\left(22.7^{\circ}\right)$, due to the increasing bulkiness of the $N$-alkyl group, see Figure 4 and Table 2 . The amino group is practically not twisted for the NXC5 compounds: $\operatorname{NMC5}\left(2.7^{\circ}\right), \operatorname{NEC5}\left(1.1^{\circ}\right)$ and NIC5 $\left(1.4^{\circ}\right)$.

The calculated angles $\theta$ for NMC6 are $19.6^{\circ},{ }^{19} 0^{\circ},{ }^{20}$ and $0.1^{\circ}, 22$ only the last two values being close to the experimental (crystal) angle of $3.3^{\circ}$. For NTC6, the calculations of $\theta$ find $32.1^{\circ},{ }^{19} 32.5^{\circ},{ }^{20}$ and $26.8^{\circ} .^{22}$ Although these results agree among each other in that the amino twist angle of NTC6 is substantial, they are clearly larger than the experimental $\theta$ of $22.7^{\circ}$ (Table 2).

Amino Pyramidal Angle $\boldsymbol{\varphi}$ and Sum of Bond Angles $\boldsymbol{\Sigma} \boldsymbol{N}$. The experimental amino pyramidal angle $\varphi$ in the series NXC6, NTC6 $\left(9.6^{\circ}\right), \operatorname{NIC6}\left(7.2^{\circ}\right), \operatorname{NEC6}\left(2.0^{\circ}\right)$ and NMC6 $\left(15.5^{\circ}\right)$, does not show a correlation with the amino twist angle $\theta$ (Table $2)$ NMC6 with a relatively small $\theta\left(3.3^{\circ}\right)$ has the largest $\varphi$ $\left(15.5^{\circ}\right)$. The same is found for the pyramidal angle $\varphi$ of the effectively planar NXC5 $\left(\theta \leq 5^{\circ}\right)$ : NIC5 $\left(28.6^{\circ}\right)$, NEC5 $\left(7.7^{\circ}\right)$,

(33) The energy gap $\Delta E\left(S_{1}, S_{2}\right)$ has been approximated in previous publications as the experimentally accessible difference between the lowest-energy vibrational peak $\tilde{v}\left(\mathrm{~S}_{1}{ }^{0}\right.$, abs $)$ of the $\mathrm{S}_{1}$ absorption band and the $\mathrm{S}_{2}$ absorption maximum $\tilde{v}^{\max }\left(\mathrm{S}_{2}, \mathrm{abs}\right)$. The correct energy difference $\Delta E\left(\mathrm{~S}_{1}, \mathrm{~S}_{2}\right)=\tilde{v}^{\max }\left(\mathrm{S}_{2}, \mathrm{abs}\right)-\tilde{v}^{\max }\left(\mathrm{S}_{1}, \mathrm{abs}\right)$, to be used in a comparison of the computed and experimental vertical (FranckCondon) absorption energies is estimated to be around $1100 \mathrm{~cm}^{-1}$ smaller, as discussed in the text

(34) Bulliard, C.; Allan, M.; Wirtz, G.; Haselbach, E.; Zachariasse, K. A.; Detzer, N.; Grimme, S. J. Phvs. Chem. A 1999, 103, 7766.

(35) Carsey, T. P.; Findley, G. L.; McGlynn, S. P. J. Am. Chem. Soc. 1979, $101,4502$.

(36) Birks, J. B. Photophysics of Aromatic Molecules; Wiley: London, 1970

(37) Yoshihara, T.; Galievsky, V. A.; Druzhinin, S. I.; Saha, S.; Zachariasse, K. A. Photochem. Photobiol. Sci. 2003, 2, 342.

(38) von Bülow, R. Master Thesis (Diplomarbeit), Universität Göttingen: Göttingen, 1996.

(39) Heine, A.; Herbst-Irmer, R.; Stalke, D.; Kühnle, W.; Zachariasse, K. A. Acta Crystallogr. 1994, B50, 363.
NMC5 $\left(37.0^{\circ}\right)$, as compared with the $\theta$ twist angles of $1.4,1.1$, and $2.7^{\circ}$. The angle $\varphi$ shows a correlation with the sum $\Sigma N$ of the bond angles around the amino nitrogen, the molecules $\operatorname{NMC6}\left(\varphi=15.5^{\circ} ; \Sigma N=356.4^{\circ}\right)$ and NMC5 $\left(\varphi=37.0^{\circ} ; \Sigma N\right.$ $=346.3^{\circ}$ ) with the largest $\varphi$ having the smallest $\Sigma N$ (Table 2). In contrast to NXC6 and $\mathrm{NXC5}, \varphi$ becomes larger and $\Sigma N$ becomes smaller with increasing amino twist angle $\theta$ for DMABN $\left(2.2^{\circ}(\theta) ; 8.6^{\circ}(\varphi) ; 358.5^{\circ}(\Sigma N)\right)$, DIABN $\left(14.3^{\circ}\right.$; $\left.15.2^{\circ} ; 357.2^{\circ}\right)$ and MMD $\left(57.4^{\circ} ; 24.4^{\circ} ; 353.8^{\circ}\right)$, see Table 2.

The calculated amino pyramidal angle $\varphi$ for NMC6, determined according to our definition (the angle between the vector $\mathrm{N}(1) \mathrm{C}(9)$ and the plane $\mathrm{C}(2) \mathrm{N}(1) \mathrm{C}(13)$, see Chart 2 and Figure $4)$, is $26.3^{\circ},{ }^{19} 28.7^{\circ},{ }^{20}$ and $24.8^{\circ},{ }^{22}$ these three results all are nearly the double of the experimental angle of $15.5^{\circ}$. The sum of the angles $\Sigma N$ around N(1) for NMC6, directly related with $\varphi$ (see above), equals $351.3^{\circ 20}$ and $353.6^{\circ},{ }^{22}$ as compared with $356.4^{\circ}$ for $\Sigma N$ from the crystal (Table 2 ), this difference being similar to that found above for $\varphi$. For NTC6, the computed $\varphi$ angles are: $19.5^{\circ},{ }^{19} 3.2^{\circ},{ }^{20}$ and $18.9^{\circ} .^{22}$ The angles $\varphi$ of refs 19 and 22 are about double the experimental value of $9.6^{\circ}$, whereas that from ref 20 is considerably smaller. The same trend is also reflected in $\Sigma N$ (Table 2). The substantial deviations between the experimental and calculated pyramidal angles for NMC6 and NTC6 would merit further computational attention.

Especially in the case of molecules with a relatively small barrier for bond twisting, crystal packing may in principle limit the significance of a comparison between crystal twist angles and those present in the vapor phase or in solution. An example is $N$-phenylcarbazole, for which two molecules with strongly different twist angles $\left(54^{\circ}\right.$ and $\left.78^{\circ}\right)$ are present in the asymmetric unit. $^{40}$

Amino-Alkyl Bond Length $\mathbf{N}(\mathbf{X})-\mathbf{C}(\mathbf{1 3})$. For the experimental $\mathrm{N}(1)-\mathrm{C}(13)$ bond length in the series NXC6, a striking development is found (Table 2): $144.4 \mathrm{pm}$ (NMC6), $146.7 \mathrm{pm}$ (NEC6), 147.4 pm (NIC6) and 149.3 pm (NTC6), an increase of 4.9 pm from NMC6 to NTC6. A similar observation is made for $\mathrm{N}(7)-\mathrm{C}(13)$ of DIABN (148.2 pm) as compared with DMABN (144.8 pm), Table 2. Likewise, the bond length $\mathrm{N}(1)-\mathrm{C}(13)$ is larger for NIC5 (147.6 pm) than for NEC5 (144.6 pm) and NMC5 (145.7 pm). It is thus seen that the increase in steric hindrance exerted by the amino alkyls (methyl to isopropyl and tert-butyl) not only leads to an larger amino twist angles as mentioned above, but this steric strain is also relieved by a lengthening of the $\mathrm{N}(1)-\mathrm{C}(13)$ bond. Similarly, the amino angle $\mathrm{C}(2)-\mathrm{N}(1)-\mathrm{C}(13)$ in NXC6 opens up while increasing the strain when going from the methyl to the tert-butyl substituent: $116.9^{\circ}$ (NMC6), $115.9^{\circ}$ (NEC6), $117.0^{\circ}$ (NIC6), 123.4 $4^{\circ}$ (NTC6).

The calculated $\mathrm{N}(1)-\mathrm{C}(13)$ bond lengths for NTC6, 147.9 $\mathrm{pm}^{20}$ and $148.4 \mathrm{pm}^{22}$ are both around $1 \mathrm{pm}$ shorter than in the crystal (149.3 pm). For NMC6, in contrast, the computed $\mathrm{N}(1)-\mathrm{C}(13)$ bond length with $144.6 \mathrm{pm}^{20}$ and $144.9 \mathrm{pm},{ }^{22}$ is the same as the experimental value of $144.4 \mathrm{pm}$ (Table 4). In general, the calculated bond lengths are expected ${ }^{41-43}$ to be 1 pm larger, as will be discussed below.

(40) Avendaño, C.; Espada, M.; Ocaña, B.; Garcia-Granda, S.; del Rosario Diaz, M.; Tejerina, B.; Gómez-Beltrán, F.; Martinez, A.; Eiguero, J. J. Chem. Soc., Perkin Trans. 2 1993, 1547.

(41) Rademacher, P. Strukturen Organischer Moleküle - Physikalische Organische Chemie, Bd. 2; Klessinger, M., Ed.; VCH, Weinheim, NY, 1987; p 55 ff.

(42) Domenicano, A., Hargittai, H., Eds. Accurate Molecular Structures. Their Determination and Importance; Oxford University Press: Oxford, UK, 1992. 


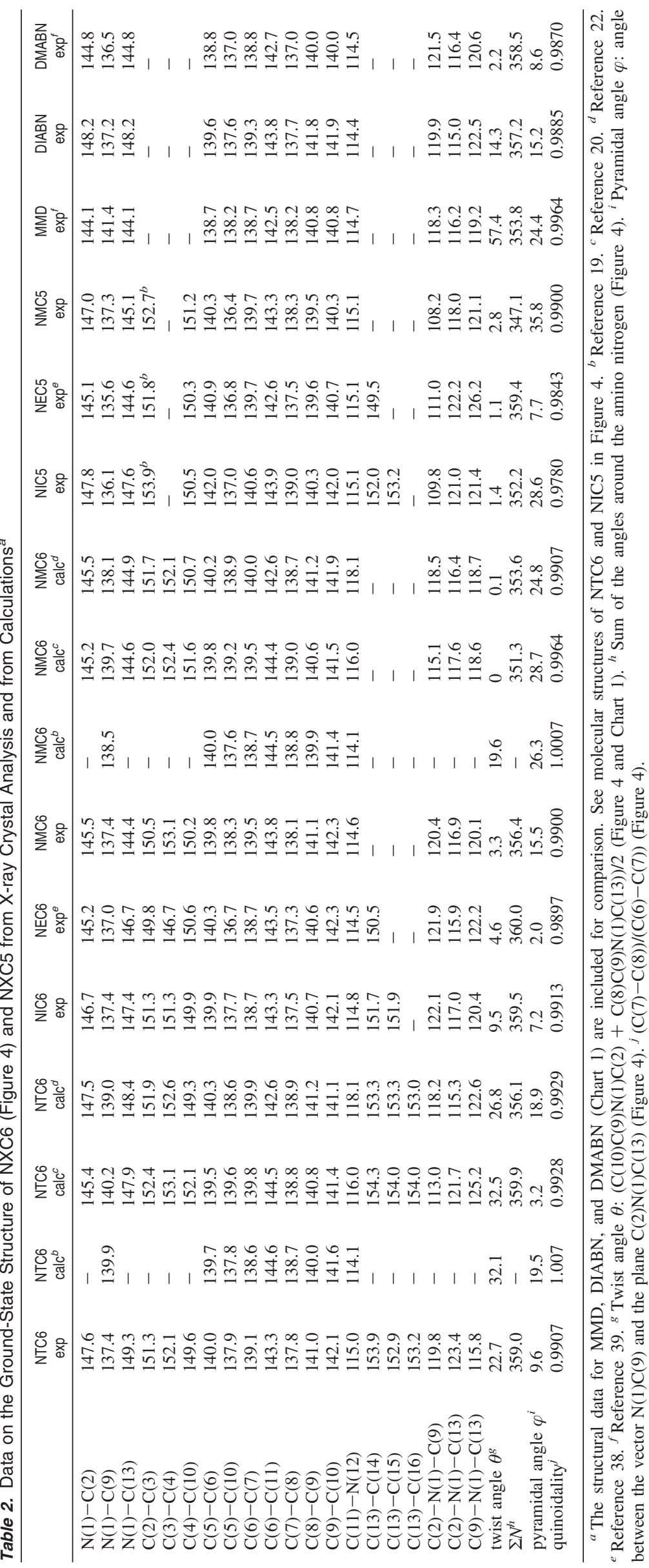




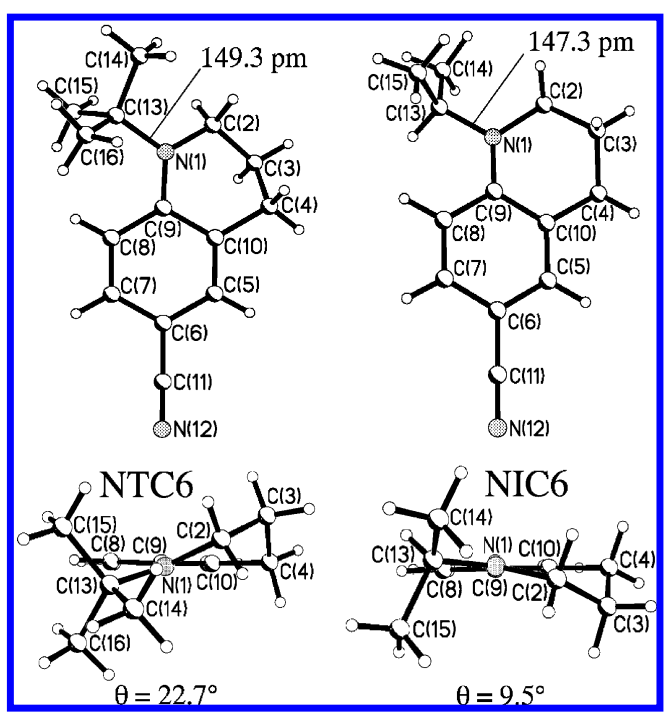

Figure 4. Crystal structures of NTC6 (left) and NIC6 (right). For both molecules, a view from above and one along the axis from the amino nitrogen to the cyano group is presented. The lengths for the alkylamino nitrogen bond $\mathrm{C}(13)-\mathrm{N}(1)$ and the amino twist angle $\theta=(\mathrm{C}(10) \mathrm{C}(9) \mathrm{N}(1) \mathrm{C}(2)$ $+\mathrm{C}(8) \mathrm{C}(9) \mathrm{N}(1) \mathrm{C}(13)) / 2$, are indicated in the structures. The pyramidal angle $\varphi$ (not shown) is the angle between the vector $\mathrm{N}(1) \mathrm{C}(9)$ and the plane $\mathrm{C}(2) \mathrm{N}(1) \mathrm{C}(13)$, see Chart 2.

Chart 2. Dihedral angles $\psi_{1}$ and $\psi_{2}$, Used To Define the Twist Angle $\theta=\left(\psi_{1}+\psi_{2}\right) / 2=(\mathrm{C}(10) \mathrm{C}(9) \mathrm{N}(1) \mathrm{C}(2)+$

$\mathrm{C}(8) \mathrm{C}(9) \mathrm{N}(1) \mathrm{C}(13)) / 2$; Pyramidal Angle $\varphi$ Is the Angle between the Vector $\mathrm{N}(1) \mathrm{C}(9)$ and the Plane $\mathrm{C}(2) \mathrm{N}(1) \mathrm{C}(13)$ for NTC6 and NIC5, see Figure 4

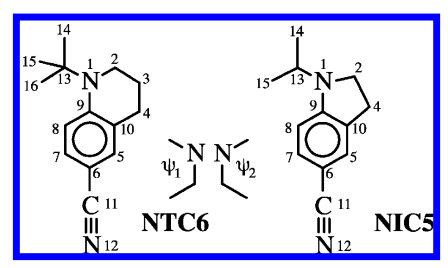

$\mathbf{N}$-Phenyl Bond Length $\mathbf{N}(\mathbf{1})-\mathbf{C}(\mathbf{9})$. For the crystalline aminobenzonitriles DMABN, DIABN, and MMD, the increasing steric strain exerted on the amino nitrogen in this series, leading to larger twist angles $\theta$ and less conjugation, is relieved by lengthening the $\mathrm{N}(1)-\mathrm{C}(9)$ bond when $\theta$ becomes larger: DMABN (136.5 pm; 2.2 ${ }^{\circ}$ ), DIABN (137.2 pm; 14.3 ${ }^{\circ}$ ), and MMD (141.4 pm; 57.4 ${ }^{\circ}$, see Table 2. Such a correlation is not observed for the experimental crystal data of NXC6 and NXC5, the $N$-phenyl bond length remaining effectively constant, independent of $\theta$ : NMC6 (137.4 pm; 3.3 $)$, NEC6 (137.0 pm; 4.6 $6^{\circ}$, NIC6 (137.4 pm; 9.5 $)$, NTC6 (137.4 pm; 22.7º, NMC5 (137.2 pm; $\left.2.7^{\circ}\right)$, NEC5 (135.6 pm; 1.1 $)$, NIC5 (136.1 pm; $1.4^{\circ}$ ). Apparently, the presence of the alicyclic ring in NXC6 and NXC5 results in a structural fixation of the molecules and consequently in a practically constant $(137.2 \pm 0.2 \mathrm{pm})$ bond length $\mathrm{N}(1)-\mathrm{C}(9)$.

In all three computational approaches, the $\mathrm{N}(1)-\mathrm{C}(9)$ bond length of NTC6 is substantially larger than the experimental length of $137.4 \mathrm{pm}: 139.9 \mathrm{pm}(+2.5 \mathrm{pm}),{ }^{19} 140.2 \mathrm{pm}(+2.8$ $\mathrm{pm}),{ }^{20} 139.0 \mathrm{pm}(+1.6 \mathrm{pm}),{ }^{22}$ see Table 2. Also for NMC6, the calculated $\mathrm{N}(1)-\mathrm{C}(9)$ bond, with $138.5 \mathrm{pm}(+1.1 \mathrm{pm}),{ }^{19}$ $139.7 \mathrm{pm}(+2.3 \mathrm{pm})^{20}$ and $138.1 \mathrm{pm}(+0.7 \mathrm{pm}),{ }^{22}$ is clearly longer than the $137.4 \mathrm{pm}$ determined from the crystal. The larger bond lengths obtained in the calculations would lead to a reduction of the electronic coupling between the amino group and the phenyl ring and possibly also to a lower rotational barrier around the amino-phenyl bond, as compared with the experimental situation.

Cyano Bond Length $\mathbf{C}(\mathbf{1 1})-\mathbf{N}(\mathbf{1 2})$. The experimental cyano bond length $\mathrm{C}(11)-\mathrm{N}(12)$ of NXC6, with a mean value of 114.7 $\mathrm{pm}$, is similar to that $(114.5 \mathrm{pm})$ for DMABN, DIABN, and MMD (Table 2). For NXC5, a mean length of $115.1 \mathrm{pm}$ is determined. Among the calculations for C(11) - N(12) of NMC6 and NTC6, somewhat surprisingly, substantially different bond lengths are obtained: $114.1 \mathrm{pm},{ }^{19} 116.0 \mathrm{pm},{ }^{20}$ and $118.1 \mathrm{pm},{ }^{22}$ whereas the experimental bond length is $115.0 \mathrm{pm}$ for NTC6 and $114.6 \mathrm{pm}$ for NMC6 (Table 2).

Phenyl-Cyano Bond Length $\mathbf{C}(6)-\mathbf{C}(11)$. The experimental bond length $\mathrm{C}(6)-\mathrm{C}(11)$ is $143.3 \mathrm{pm}$ for NTC6 and $143.8 \mathrm{pm}$ for NMC6. The aminobenzonitriles in Table 2, have similar bond lengths $\mathrm{C}(6)-\mathrm{C}(11)$ : 143.3 pm (NIC6), 143.5 pm (NEC6), 143.5 $\pm 0.4 \mathrm{pm}$ (NXC5), $142.7 \mathrm{pm}$ (DMABN), $143.8 \mathrm{pm}$ (DIABN), $142.5 \mathrm{pm}(\mathrm{MMD})$. The calculated $\mathrm{C}(6)-\mathrm{C}(11)$ bond length of NTC6 is with $144.6 \mathrm{pm}^{19}$ and $144.5 \mathrm{pm}^{20}$ about $1 \mathrm{pm}$ larger than the experimental value of $143.3 \mathrm{pm}$, whereas a shorter length (142.6) is obtained in ref 22. A similar discrepancy is found for NMC6 (Table 2). These differences in bond length will likewise affect the electronic coupling between the cyano and phenyl groups, similar to what was discussed above for the amino-phenyl bond $\mathrm{N}(1)-\mathrm{C}(9)$.

Phenyl Ring Bond Lengths. In the phenyl ring of the crystalline NXC6 molecules, in particular the bond length $\mathrm{C}(9)-\mathrm{C}(10)$ is larger than that of DMABN: $142.2 \pm 0.1 \mathrm{pm}$ (mean value) as compared with $140.0 \mathrm{pm}$ (Table 2). This is again, as with the constant amino-phenyl bond (see above), caused by the presence of the alicyclic ring. The other phenyl ring bond lengths of the NXC6, except $\mathrm{C}(6)-\mathrm{C}(7)$, are all around $1 \mathrm{pm}$ larger than those of DMABN (Table 2). The asymmetry of the phenyl ring in the NXC6 is hence larger than with DMABN. An even more irregular pattern is observed for the phenyl bonds of the NXC5.

For DIABN, the phenyl bond lengths all are larger than for DMABN, especially $\mathrm{C}(3)-\mathrm{C}(4)$ with a difference of around 2 pm: $141.9 \mathrm{pm}$ as compared with $140.0 \mathrm{pm}$, see Table 2, its similarity to the NXC6 molecules being due to the bulky isopropyl substituents. The phenyl bond lengths $\mathrm{C}(2)-\mathrm{C}(3)$ and $\mathrm{C}(3)-\mathrm{C}(4)$ of $\mathrm{MMD}$ are around $1 \mathrm{pm}$ larger than those of DMABN, whereas $\mathrm{C}(1)-\mathrm{C}(2)$ is found to be equal: $138.2 \mathrm{pm}$ (137.0 pm) for $\mathrm{C}(2)-\mathrm{C}(3), 140.8 \mathrm{pm}(140.0 \mathrm{pm})$ for $\mathrm{C}(3)-\mathrm{C}(4)$ and $138.7 \mathrm{pm}(138.8 \mathrm{pm})$ for $\mathrm{C}(1)-\mathrm{C}(2)$. This difference, caused by the strong twist of the amino group $\left(\theta=57.4^{\circ}\right)$, reduces the quinoidality $(\mathrm{C}(2)-\mathrm{C}(3)) /(\mathrm{C}(1)-\mathrm{C}(2))$ for the phenyl ring of MMD (0.9964) as compared to that of DMABN (0.9870), see Table 2.

The comparison between the calculated and the experimental crystal data for the phenyl ring bond lengths of NTC6, NMC6 and DMABN reveals an irregular pattern. The bond lengths of NTC6 from ref 19 are at most around $0.5 \mathrm{pm}$ smaller than the experimental data, except for $\mathrm{C}(8)-\mathrm{C}(9)$, for which $140.0 \mathrm{pm}$ is calculated as compared with $141.0 \mathrm{pm}$ from the crystal. In ref 20 the $\mathrm{C}(5)-\mathrm{C}(10)$ bond $(139.6 \mathrm{pm})$ is $1.7 \mathrm{pm}$ longer than for the crystal $(137.9 \mathrm{pm})$, whereas for the other phenyl bonds differences between $-0.7 \mathrm{pm}(\mathrm{C}(9)-\mathrm{C}(10))$ and $1.0 \mathrm{pm}$ $(\mathrm{C}(7)-\mathrm{C}(8))$ are obtained. In ref 22 the phenyl bond lengths are mostly larger than those of the crystal, from $0.2 \mathrm{pm}$ $(\mathrm{C}(8)-\mathrm{C}(9))$ to $1.1 \mathrm{pm}(\mathrm{C}(7)-\mathrm{C}(8))$, except for $\mathrm{C}(9)-\mathrm{C}(10)$, which is smaller by $1.0 \mathrm{pm}$. These deviations between the computed and crystal phenyl bond lengths also lead to differ- 
ences in the ring quinoidality of NTC6: $1.007,{ }^{19} 0.9928,{ }^{20}$ $0.9929^{22}$ as compared with the experimental 0.9907 (Table 2)

Bonds in the Alicyclic Ring of NTC6 and NMC6. The experimental bond lengths in the six-membered alicyclic ring of NTC6 are 147.6 pm (N(1)-C(2)), $151.3 \mathrm{pm}(\mathrm{C}(2)-\mathrm{C}(3))$ $152.1 \mathrm{pm}(\mathrm{C}(3)-\mathrm{C}(4))$, and $149.6 \mathrm{pm}(\mathrm{C}(4)-\mathrm{C}(10))$. The calculated bond lengths in ref 22 are within $+0.6 \mathrm{pm}$ from the experimental values, with the largest difference for $\mathrm{C}(2)-\mathrm{C}(3)$. Larger differences occur with the computations of ref 20: -2.2 $\mathrm{pm}$ for $\mathrm{N}(1)-\mathrm{C}(2),-1.1 \mathrm{pm}$ for $\mathrm{C}(2)-\mathrm{C}(3),-1.0 \mathrm{pm}$ for $\mathrm{C}(3)-\mathrm{C}(4)$, and $+2.5 \mathrm{pm}$ for $\mathrm{C}(4)-\mathrm{C}(10)$. In the case of NMC6, the following differences are found between the experimental and calculated bond lengths: $\mathrm{N}(1)-\mathrm{C}(2)=145.5 \mathrm{pm}:+0.3$ $\mathrm{pm},{ }^{20} 0.0 \mathrm{pm} ;{ }^{22} \mathrm{C}(2)-\mathrm{C}(3)=150.5 \mathrm{pm}:-1.5 \mathrm{pm},{ }^{20}-1.2 \mathrm{pm} ;{ }^{22}$ $\mathrm{C}(3)-\mathrm{C}(4)=153.1 \mathrm{pm}:+0.7 \mathrm{pm},{ }^{20}+1.0 \mathrm{pm} ;{ }^{22}$ and $\mathrm{C}(4)-\mathrm{C}(10)$ $150.2 \mathrm{pm}:-1.4 \mathrm{pm},{ }^{20}-0.5 \mathrm{pm}^{22}$

Overall Comparison of Calculated and Crystal Data. When comparing bond lengths obtained from X-ray crystal data at around $100 \mathrm{~K}$ with those resulting from calculations (which refer to the gas phase at $0 \mathrm{~K}$ ), one can in principle anticipate a bond length shortening of around $1 \mathrm{pm}$ for the crystal data, due to the librations at $100 \mathrm{~K}$ that are much smaller at $0 \mathrm{~K}^{41-43}$ Periodic boundary conditions and cluster embedment, not relevant for the computations, further complicate the comparison. Keeping this proviso in mind, it is seen from the discussion of the data from Table 2 in the preceding sections, that substantial differences occur between the crystal and calculated structures, in particular for the bond lengths amino-phenyl $\mathrm{N}(1)-\mathrm{C}(9)$, cyano $\mathrm{C}(11)-\mathrm{N}(12)$, amino-alkyl $\mathrm{N}(1)-\mathrm{C}(13)$ in the case of NTC6 (but not for NMC6), the amino twist angle $\theta$ of NMC6 (ref 19), the pyramidal amino angle $\varphi$ and the bond angles around the amino nitrogen. The differences between the experimental and computed data are not the same for the three calculations, see Table $2 .{ }^{19-23}$

From the overall comparison between the calculated and crystal data of NTC6, NMC6, and DMABN presented here, it is seen that the crystal bond lengths are in general not around $1 \mathrm{pm}$ shorter than the computed bond lengths, as could have been expected on the basis of the reasoning presented above..$^{41-43}$ Some crystal bond lengths are indeed shorter, but others are in fact larger than the calculated data.

Reliable structural information for benzonitriles or even anilines in the gas phase is practically not available, however, and even less so in solution. ${ }^{44-46}$ This precludes a realistic analysis of molecular structure data for such molecules, beyond the level of an internal comparison as carried out here. At any rate, the larger calculated nitrogen-phenyl and cyano-phenyl bond lengths in the NXC6 molecules as compared with the experimental results, will necessarily lead to a smaller electronic coupling of the amino nitrogen atom and cyano substituent with

(43) Colapietro, M.; Domenicano, A.; Portalone, G. J. Mol. Struct. 1984, $112,141$.

(44) Perhaps surprisingly, reliable experimental information on bond lengths and other structural properties for molecules in the vapor phase or in solution is not available, which obviously severely limits a comparison of calculated with crystal data. In the case of aminobenzonitriles, such a comparison of gas phase/crystal appears only to be possible for the related molecule aniline, for which vapor phase (microwave, ref 45) data exist. The aniline crystal data, however, are of limited value in this respect, due to the absence of molecular symmetry of the reported bond lengths in ref 46.

(45) Lister, D. G.; Tyler, J. K.; Høg, J. H.; Wessel Larsen, N. J. Mol. Struct. 1974, $23,253$.

(46) Fukuyo, M.; Hirotsu, K.; Higuchi, T. Acta Crystallogr. 1982, B38, 640. the phenyl moiety in e.g. NTC6 and consequently also to a lowering of the rotational barrier around the $N$-phenyl bond as compared to that to be encountered experimentally. In this connection, it is important to recall that the length of a single bond $\mathrm{C}-\mathrm{N}$ is 147 and $128 \mathrm{pm}$ for a double bond $\mathrm{C}=\mathrm{N},{ }^{47}$ which means that $1 \mathrm{pm}$ is in fact about $5 \%$ of this difference and hence will affect the rotational barriers.

NTC6, NMC6, and DMABN in the Gas Phase. Energies of the $S_{1}, S_{2}, L E$, and ICT States from Spectra and Extrapolation. As discussed above, dual fluorescence (LE + ICT) is observed with NTC6 in the gas phase (Figure 2b, Table 1), but only LE emission is found for DMABN and NMC6 vapors (Figures 1a and 2a). ${ }^{25,32}$ Therefore, whereas the $S_{1}$ and $S_{2}$ absorption energetics and the maxima of the LE fluorescence band $\tilde{v}^{\max }(\mathrm{LE})$, see Figure 5, ${ }^{12,48}$ can be obtained from the gas phase absorption and emission spectra of all three molecules (Figures 1a and 2), $\tilde{v}^{\max }$ (ICT) can only be determined directly for NTC6. In the case of DMABN, the ICT fluorescence characteristics must hence come from extrapolation, employing a solvent series including alkanes and $\mathrm{pFMCH}$, a solvent with properties bordering on those of the gas phase (Table 3). ${ }^{25,36,37}$ For NMC6, ICT emission is not observed; ${ }^{1,3,32}$ it is even absent in a polar solvent such as $\mathrm{MeCN}$, so that the energy of its ICT state cannot be extracted from experimental data. Similarly, the gas phase energies for the $S_{1}, S_{2}$, LE, and ICT states of DMABN, NMC6, and NTC6 also can be determined by extrapolation, employing a solvent series from the polar $\mathrm{MeCN}$ to the nonpolar alkanes and $\mathrm{pFMCH}$. The results of this extrapolation are in good agreement with the vapor phase results.

A possible sliding down the slope of the $S_{2}$ potential energy surface and a branching to LE and ICT near the $S_{2}$ energy minimum (or conical intersection), as a direct population pathway, bypassing LE as a precursor, has been found not to take place with NTC6, DMABN, and other D/A molecules in solution: the ICT state is formed exclusively from LE. 2,16-18,21,27,29

From the directly measured and the extrapolated spectral data so obtained, the excited state LE/ICT energy diagrams for NTC6, NMC6, and DMABN in the gas phase can then be constructed. These diagrams contain the energies of relevant excited singlet, LE, and ICT states, together with the LE and ICT fluorescence maxima and their corresponding FranckCondon (FC) states (Figure 5). DMABN will be discussed first.

DMABN. Gas Phase LE/ICT Energy Diagram. The gas phase LE/ICT energy diagram of DMABN is constructed in the following manner. From the gas phase absorption spectrum of DMABN (Figure 1a), ${ }^{25}$ the FC energies for the $S_{1}$ and $S_{2}$ states reached by absorption from $S_{0}$ can be determined. Whereas the absorption maximum $\tilde{v}^{\max }\left(\mathrm{S}_{2}, \mathrm{abs}\right)=36830 \mathrm{~cm}^{-1}$ comes directly from the spectrum (Table 1$), \tilde{v}^{\max }\left(\mathrm{S}_{1}, \mathrm{abs}\right)$ is hidden under the stronger $S_{2}$ absorption. The energy of the first $0-0$ absorption peak $\tilde{v}\left(\mathrm{~S}_{1}{ }^{0}, \mathrm{abs}\right)=32210 \mathrm{~cm}^{-1}$ can be determined (Figure 1a) and is listed in Tables 1 and 3. An estimate of $\tilde{v}^{\max }\left(\mathrm{S}_{1}, \mathrm{abs}\right)$ can

(47) March, J. Advanced Organic Chemistry, 4th ed.; Wiley: New York, 1992; p 21.

(48) In the LE $\rightarrow$ ICT reaction scheme represented by Figure $5, S_{1}$ is the sole precursor for the ICT state, see ref 12 . In this connection, the following quotation from ref 21 is important: 'We expect that the internal conversion directly to $\mathrm{S}_{1}$-LE will be favored, because the minimum structure on the crossing seam is not twisted in $\mathrm{S}_{2}$-(P)ICT. Decay at low torsion angles is probably even more favored in solution because of the friction with the solvent. Thus, relaxation to $S_{1}$-LE is favored both energetically and dynamically. This could explain why all of the experimental evidence in solution points to $\mathrm{S}_{1}$-LE as the sole precursor of ICT'. 




Figure 5. Potential energy surfaces for the ground state $\mathrm{S}_{0}$ and the excited states $S_{1}, S_{2}$, LE, and ICT. When excited to the $S_{2}$ state, the system relaxes by internal conversion to the equilibrated locally excited LE state, with an energy $E\left(\mathrm{~S}_{1}\right)=E(\mathrm{LE})$ above $\mathrm{S}_{0}$. The intramolecular charge transfer (ICT) reaction proceeds from the LE to the ICT state, with a reaction barrier $E_{\mathrm{a}}$ and an enthalpy difference $\Delta H$. Fluorescence from the LE and ICT states, with emission maxima $\tilde{v}^{\max }(\mathrm{LE})$ and $\tilde{v}^{\max }(\mathrm{ICT})$, reaches the corresponding Franck-Condon states $E(\mathrm{FC}, \mathrm{LE})$ and $E(\mathrm{FC}, \mathrm{ICT}) . \Delta E\left(\mathrm{~S}_{1}, \mathrm{~S}_{2}\right)$ is the energy difference $\tilde{v}^{\max }\left(\mathrm{S}_{2}, \mathrm{abs}\right)-\tilde{v}^{\max }\left(\mathrm{S}_{1}\right.$, abs $)$. The horizontal coordinate $\xi$ comprises all molecular changes accompanying the LE $\rightarrow$ ICT reaction, such as changes in bond lengths and bond angles. Detailed experimental information on these changes is not available.

be obtained as follows. From the absorption spectrum of DMABN and of three of its analogues, 4-aminobenzonitrile $(\mathrm{ABN}), \mathrm{NMC6}$, and 4-(dimethylamino)benzotrifluoride (DMCF3), an energy difference of $1100 \mathrm{~cm}^{-1}$ between $\tilde{v}\left(\mathrm{~S}_{1}{ }^{0}, \mathrm{abs}\right)$ and $\tilde{v}^{\max }\left(\mathrm{S}_{1}, \mathrm{abs}\right)$ is determined, see Figure 6 . The same value of $1100 \mathrm{~cm}^{-1}$ appears as the progression in the $S_{1}$ absorption bands of these molecules in alkanes (Figure 6). The energy gap $\Delta E\left(\mathrm{~S}_{1}, \mathrm{~S}_{2}\right)$ between $\mathrm{S}_{2}$ and $\mathrm{S}_{1}$, equal to $\tilde{v}^{\max }\left(\mathrm{S}_{2}, \mathrm{abs}\right)$ $\tilde{v}^{\max }\left(\mathrm{S}_{1}, \mathrm{abs}\right)$, can hence be calculated by subtracting $1100 \mathrm{~cm}^{-1}$ from the energy difference $\tilde{v}^{\max }\left(\mathrm{S}_{2}, \mathrm{abs}\right)-\tilde{v}\left(\mathrm{~S}_{1}{ }^{0}, \mathrm{abs}\right),{ }^{33}$ see Tables 1 and 3 . The energies so obtained for $\tilde{v}\left(\mathrm{~S}_{1}{ }^{0}, \mathrm{abs}\right)$, $\tilde{v}^{\max }\left(\mathrm{S}_{1}, \mathrm{abs}\right)$ and $\tilde{v}^{\max }\left(\mathrm{S}_{2}, \mathrm{abs}\right)$ of DMABN in the vapor phase appear as $\mathrm{S}_{1}{ }^{0}, \mathrm{~S}_{1}$, and $\mathrm{S}_{2}$ in Figure 7.

The energy $E(\mathrm{LE})$ of the equilibrated LE state of DMABN in the gas phase, see Figure 5 , is taken to be equal to $\tilde{v}\left(\mathrm{~S}_{1}{ }^{0}, \mathrm{abs}\right)$, see Figure 1a and Tables 1 and 3. The enthalpy difference between the LE and ICT states $\Delta H=4.5 \mathrm{~kJ} / \mathrm{mol}$, needed for the determination of the energy $E(\mathrm{ICT})(=E(\mathrm{LE})+\Delta H)$ of the equilibrated ICT state, is obtained from a plot of experimental values for $\Delta H$ vs the solvent polarity parameter $f(\varepsilon)-1 /$ $2 f\left(n^{2}\right)$, see eqs 2 and 3, by extrapolation to the gas phase. ${ }^{49}$ The $\Delta H=-2.9 \mathrm{~kJ} / \mathrm{mol}$ for DMABN in $n$-hexane (used for NTC6

(49) The gas phase ICT formation enthalpy $\Delta H$ of DMABN was determined by extrapolation from plots of $\Delta H$ vs the solvent polarity parameter $f(\varepsilon)-1 / 2 f\left(n^{2}\right)$ (eqs 2 and 3 ). The following data are used in this extrapolation (solvent, $\left.\Delta H(\mathrm{~kJ} / \mathrm{mol}), f(\varepsilon)-1 / 2 f\left(n^{2}\right)\right)$ : di- $n$-pentyl ether, $-9.7,0.268$; di- $n$-butyl ether, $-10.7,0.289$; di- $n$-propyl ether, 12.6, 0.307; diethyl ether, $-14.9,0.343$ (ref 29) and MeCN, -27.0, 0.480 (ref 24). The extrapolation gives the following results for the gas phase: $\Delta H=4.5 \mathrm{~kJ} / \mathrm{mol}$; for $n$-hexane $\left(f(\varepsilon)-1 / 2 f\left(n^{2}\right)=0.092\right)$ : $\Delta H=-2.9 \mathrm{~kJ} / \mathrm{mol}$

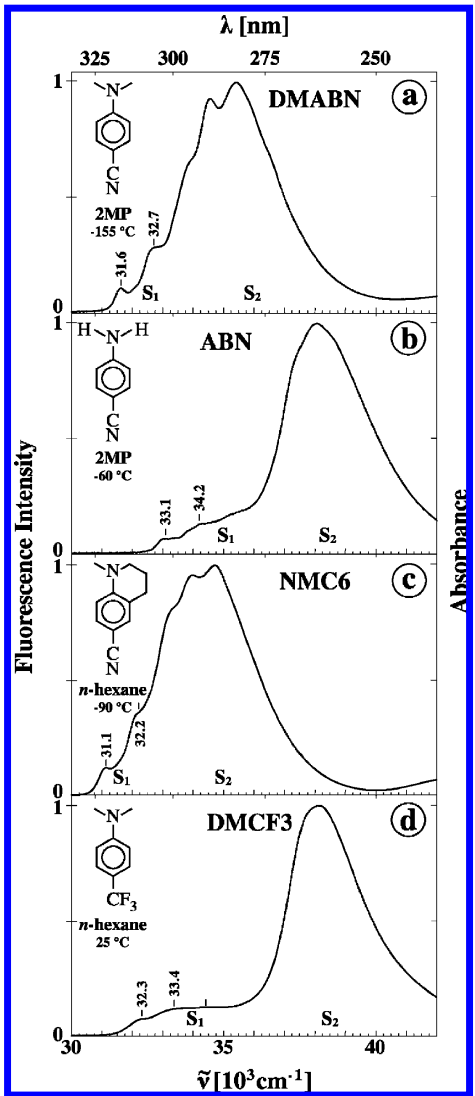

Figure 6. Absorption spectra at various temperatures of (a) DMABN, (b) $\mathrm{ABN}$, in 2-methylpentane (2MP), (c) NMC6, and (d) DMCF3, in $n$-hexane. The energies of the first and second vibrational peaks of $\mathrm{S}_{1}$, with a difference of $1100 \mathrm{~cm}^{-1}$, are indicated in the panels.

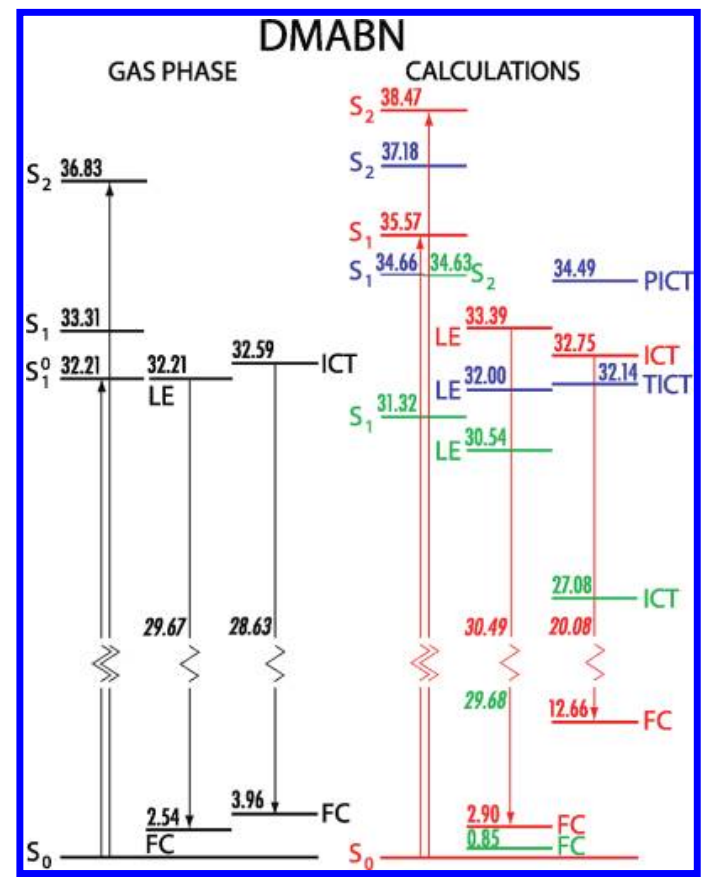

Figure 7. LE/ICT energy diagram (energies in $1000 \mathrm{~cm}^{-1}(\mathrm{kK})$ ) for the ICT reaction of DMABN, comparing the experimental data (left, Table 1) with calculations from ref 22 (red), ref 18 (blue), and ref 19 (green). $S_{1}$ and $S_{2}$ are equal to the absorption maxima $\tilde{v}^{\max }\left(\mathrm{S}_{1}, \mathrm{abs}\right)$ and $\tilde{v}^{\max }\left(\mathrm{S}_{2}, \mathrm{abs}\right)$, whereas $\mathrm{S}_{1}{ }^{0}$ is the $0-0$ energy of the $S_{1}$ absorption band. The LE and ICT emission maxima, in italics, are indicated next to the transitions (downward arrows) ending in their corresponding Franck-Condon (FC) states, with energies $E(\mathrm{FC}, \mathrm{LE})$ and $E$ (FC,ICT), see Figure 5 and Tables 1 and 3 . Note the different scale for the FC as compared with that for the excited states. 





in the following section), is obtained in a similar manner (Table 3). ${ }^{49}$ The (experimentally not observed) ${ }^{25}$ gas phase $\tilde{v}^{\max }$ (ICT) $=28630 \mathrm{~cm}^{-1}$ of DMABN is likewise determined by extrapolation, employing a plot of $\tilde{v}^{\max }$ (ICT) for a solvent series from $\mathrm{MeCN}$ to diethyl ether (DEE), ${ }^{8,29,37,50}$ against experimental data for $\tilde{v}^{\max }(\mathrm{LE})$ of DMABN, which are available ${ }^{37}$ over the entire solvent polarity scale from MeCN to the gas phase (Tables 1 and 3). The energies of the Franck-Condon (FC) states $E(\mathrm{FC}, \mathrm{LE})$ and $E(\mathrm{FC}, \mathrm{ICT})$, see Figure 5, are calculated by employing eq 4 or eq 5 , see Tables 1 and 3 .

$$
\begin{gathered}
E(\mathrm{FC}, \mathrm{LE})=E(\mathrm{LE})-\tilde{v}^{\max }(\mathrm{LE}) \\
E(\mathrm{FC}, \mathrm{ICT})=E(\mathrm{ICT})-\tilde{v}^{\max }(\mathrm{ICT})
\end{gathered}
$$

Recently, calculations on DMABN appeared employing longcorrection (LC): LC-TDDFT. ${ }^{51}$ The energies for the $\mathrm{S}_{1}$ and $\mathrm{S}_{2}$ states of DMABN, reached by vertical excitation from the equilibrated $\mathrm{S}_{0}$ ground state, are with $38390 \mathrm{~cm}^{-1}\left(\mathrm{~S}_{1}\right)$ and 40730 $\mathrm{cm}^{-1}\left(\mathrm{~S}_{2}\right)$ substantially larger than those obtained in refs 19 , 20 , and 22, outside the energy range of Figure 7 . Also the calculated LE and ICT emission maxima have considerably larger energies than the gas phase values (Table 3). The conclusion reached in ref 51 that the fluorescence spectrum of DMABN in MeCN does not contain a LE emission, is in clear contradiction with experimental observation. ${ }^{29}$ It hence appears that with present computational approaches even the calculation of absorption spectra sometimes presents difficulties with molecules such as DMABN.

NTC6. Gas Phase LE/ICT Energy Diagram. The data for $\tilde{v}^{\max }\left(\mathrm{S}_{2}, \mathrm{abs}\right), \tilde{v}^{\max }(\mathrm{LE})$, and $\tilde{v}^{\max }(\mathrm{ICT})$ of NTC6 in the vapor phase can be taken directly from the gas phase absorption and fluorescence spectra (Figure 2b, Table 1). The $S_{1}$ band is not visible in the absorption spectrum, being covered by the $S_{2}$ band similar to what was found in solution. ${ }^{1}$ Therefore, for $\tilde{v}\left(\mathrm{~S}_{1}{ }^{0}, \mathrm{abs}\right)$, equal to $E(\mathrm{LE})$ (see Figure 5), the value of $31770 \mathrm{~cm}^{-1}$ determined for NMC6 is adopted, as discussed above (Table 1). The gas phase $\Delta H$ of the ICT reaction is estimated as 5.0 $\mathrm{kJ} / \mathrm{mol},{ }^{52}$ obtained from the $-2.4 \mathrm{~kJ} / \mathrm{mol}$ for NTC6 in $n$-hexane, ${ }^{2}$ by adding the difference in $\Delta H$ between the gas phase and $n$-hexane of $7.4 \mathrm{~kJ} / \mathrm{mol}$ determined ${ }^{49}$ for DMABN (Table 3 ). In this manner, an energy $E(\mathrm{ICT})=E(\mathrm{LE})+\Delta H$ of 32200 $\mathrm{cm}^{-1}$ is found (Figure 8). As Amatatsu carried out calculations for NTC6 in an alkane solvent, ${ }^{19}$ data for NTC6 in $n$-hexane and $\mathrm{pFMCH}$ are also included in Table 3 . The energies of the Franck-Condon states $E(\mathrm{FC}, \mathrm{LE})$ and $E(\mathrm{FC}, \mathrm{ICT})$, see Figure 5 , are calculated by using eqs 4 and 5, see Tables 1 and 3 .

NMC6. Gas Phase LE/ICT Energy Diagram. The LE energy diagram of NMC6 in Figure 9 is similarly constructed from the absorption and LE fluorescence spectrum in the gas phase (Figure 2a) as was done for NTC6 (Figure 7). As an ICT

(50) Grobys, M. PhD Thesis; University Göttingen: Göttingen, 1997.

(51) Chiba, M.; Tsuneda, T.; Hirao, K. J. Chem. Phys. 2007, 126, 034504.

(52) The energy difference between the LE and ICT states of NTC6 vapor equals $0.43 \mathrm{kK}(5.0 \mathrm{~kJ} / \mathrm{mol}$, Figure 8$)$, slightly larger than that for DMABN $(0.38 \mathrm{kK}=4.5 \mathrm{~kJ} / \mathrm{mol}$, Figure 7$)$. Whereas $\Phi^{\prime}(\mathrm{ICT}) / \Phi(\mathrm{LE})$ $=0.44$ for NTC6 (Table 1 and Figure $2 \mathrm{~b}$ ), an ICT emission is not observed with DMABN vapor (Figure 1a), notwithstanding its smaller ICT reaction enthalpy $\Delta H$ of $4.5 \mathrm{~kJ} / \mathrm{mol}$ (Table 3 ). The estimated $\Delta H$ value of NTC6 may be less accurate than that obtained for DMABN, as it is based on a single experimental value of $-2.4 \mathrm{~kJ} / \mathrm{mol}$ for NTC6 in $n$-hexane (ref 2, Table 3). For NTC6 in the vapor phase, a $\Delta H$ somewhat smaller than that of DMABN $(4.5 \mathrm{~kJ} / \mathrm{mol})$ therefore seems to be likely, in view of the observation of ICT emission, absent with DMABN.

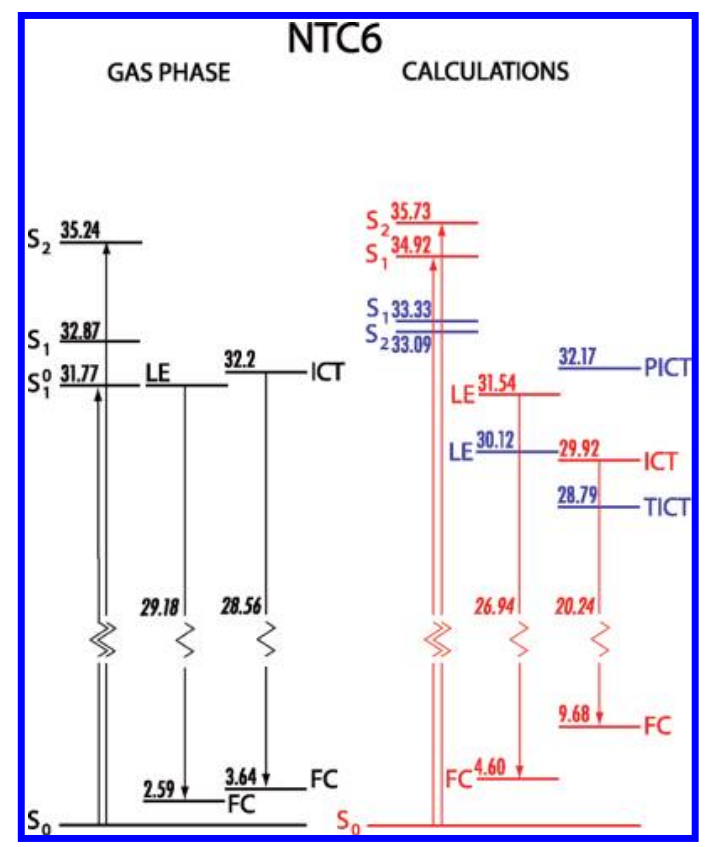

Figure 8. LE/ICT energy diagram (energies in $1000 \mathrm{~cm}^{-1}(\mathrm{kK})$ ) for the ICT reaction of NTC6, comparing the experimental data (left) with calculations of ref 22 (red) and ref 20 (blue). $S_{1}$ and $S_{2}$ are equal to the absorption maxima $\tilde{v}^{\max }\left(\mathrm{S}_{1}, \mathrm{abs}\right)$ and $\tilde{v}^{\max }\left(\mathrm{S}_{2}, \mathrm{abs}\right)$, whereas $\mathrm{S}_{1}{ }^{0}$ is the $0-0$ energy of the $S_{1}$ absorption band. The LE and ICT emission maxima, in italics, are indicated next to the transitions (downward arrows) ending in their corresponding Franck-Condon states with energies $E(\mathrm{FC}, \mathrm{LE})$ and $E(\mathrm{FC}, \mathrm{ICT})$, see Figure 5. Note the different scale for the FC as compared with that for the excited states.

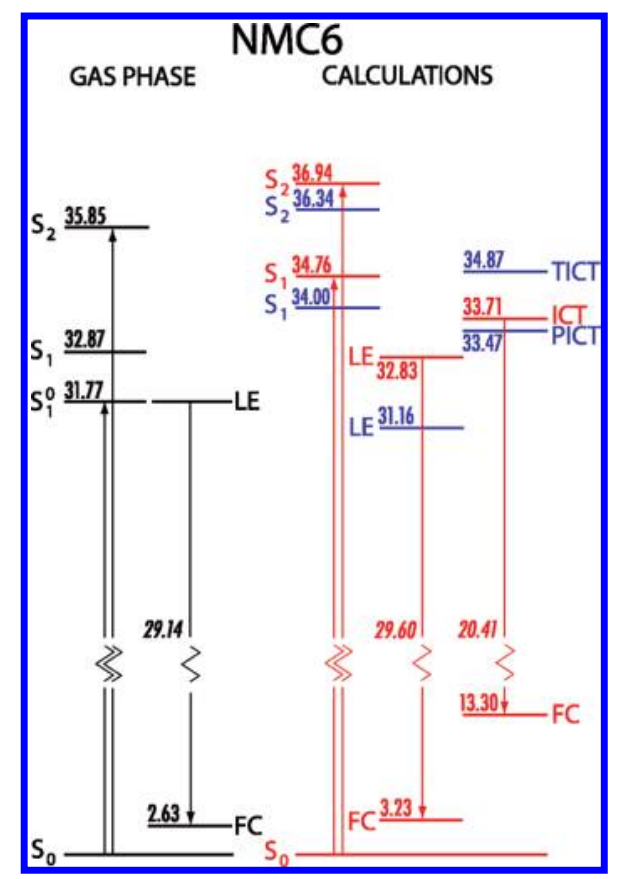

Figure 9. LE/ICT energy diagram (energies in $1000 \mathrm{~cm}^{-1}(\mathrm{kK})$ ) for the ICT reaction of NMC6, comparing the experimental data (left) with calculations of ref 22 (red) and ref 20 (blue). $S_{1}$ and $S_{2}$ are equal to the absorption maxima $\tilde{v}^{\max }\left(\mathrm{S}_{1}, \mathrm{abs}\right)$ and $\tilde{v}^{\max }\left(\mathrm{S}_{2}, \mathrm{abs}\right)$, whereas $\mathrm{S}_{1}{ }^{0}$ is the $0-0$ energy of the $S_{1}$ absorption band. The LE and ICT emission maxima, in italics, are indicated next to the transitions (downward arrows) ending in their corresponding Franck-Condon states with energies $E(\mathrm{FC}, \mathrm{LE})$ and $E$ (FC,ICT), see Figure 5. Note the different scale for the FC as compared with the excited states.

emission is not observed with NMC6, ${ }^{1,3}$ and the experimental ICT energy could not be determined. The $\Delta E\left(\mathrm{~S}_{1}, \mathrm{~S}_{2}\right)$ energy gap 
in the gas phase (Table 3 ) decreases in the series DMABN (3520 $\left.\mathrm{cm}^{-1}\right)$, NMC6 $\left(2980 \mathrm{~cm}^{-1}\right)$, NTC6 $\left(2370 \mathrm{~cm}^{-1}\right)$. In $n$-hexane a similar development is found: 2700,2500 , and $1400 \mathrm{~cm}^{-1}$ (Table $3)$.

Comparison of Gas Phase LE/ICT Energy Diagrams of NTC6, NMC6, and DMABN with Computational Results. The results of the computations on NTC6, ${ }^{20,22}$ NMC $6,{ }^{20,22}$ and DMABN $^{19-23}$ (Table 3) are shown for comparison next to the gas phase LE/ICT energy diagrams in Figures 7-9. The differences between the experimental and calculated data will now be discussed, especially concerning the energetics of the ICT state. In particular, the data for $\Delta E\left(\mathrm{~S}_{1}, \mathrm{~S}_{2}\right)$, the enthalpy difference $\Delta H$ between the LE and ICT states, $E\left(\right.$ ICT), $\tilde{v}^{\max }$ (ICT) and $E(\mathrm{FC}, \mathrm{ICT})$ are important, see Figure 5. For convenience, the energies are expressed in $\mathrm{kK}\left(1000 \mathrm{~cm}^{-1}\right)$.

Absorption Spectra $\tilde{v}^{\max }\left(\mathbf{S}_{2}, \mathbf{a b s}\right)$. As can be seen from Figure 8 and Table 3, the calculated $\tilde{v}^{\max }\left(\mathrm{S}_{2}, \mathrm{abs}\right)$ of NTC6 is either somewhat larger $(0.49 \mathrm{kK})^{22}$ or considerably smaller $(-2.15$ $\mathrm{kK})^{20}$ than the gas phase value of $35.24 \mathrm{kK}$. With NMC6 (Figure 9), the differences are $1.09 \mathrm{kK}^{22}$ and $0.49 \mathrm{kK}^{20}$ as compared with $35.85 \mathrm{kK}$ for the vapor. In the case of DMABN (Figure 7), the computed $\tilde{v}^{\max }\left(\mathrm{S}_{2}\right.$, abs $)$ are either $1.64 \mathrm{kK}^{22}$ and $0.35 \mathrm{kK}^{20}$ larger or $2.20 \mathrm{kK}^{19}$ smaller than the experimental $\mathrm{S}_{2}$ absorption maximum of $36.83 \mathrm{kK}$. Whereas in $\operatorname{ref} 20 \tilde{v}^{\max }\left(\mathrm{S}_{2}, \mathrm{abs}\right)$ is close to the gas phase data for DMABN and NMC6, a much lower value is obtained for NTC6. For the calculations in ref 22, in contrast, $\tilde{v}^{\max }\left(\mathbf{S}_{2}\right.$, abs $)$ is slightly larger than the experimental result for NTC6, but much larger differences are obtained for NMC6 and in particular for DMABN, also in ref 19.

Energy Gap $\Delta E\left(\mathbf{S}_{1}, \mathbf{S}_{2}\right)$. The calculated energy gap $\Delta E\left(\mathrm{~S}_{1}, \mathrm{~S}_{2}\right)$, defined as the energy difference $\tilde{v}^{\max }\left(\mathrm{S}_{2}, \mathrm{abs}\right)-\tilde{v}^{\max }\left(\mathrm{S}_{1}, \mathrm{abs}\right)$, decreases in the series DMABN, NMC6, NTC6: 2.90, 2.18, and $0.81 \mathrm{kK}$ in ref 22 (CC2); 2.52, 2.34, and $-0.24 \mathrm{kK}$ in ref 20 (CASPT2). Whereas these computed energy differences are lower than the experimental gas phase value for DMABN $(3.52$ $\mathrm{kK})$ and NMC6 (2.98 kK) in Table 3, the experimental $\Delta E\left(\mathrm{~S}_{1}, \mathrm{~S}_{2}\right)$ of NTC6 is with $2.37 \mathrm{kK}$ substantially larger than the $0.81 \mathrm{kK}^{22}$ and $-0.24 \mathrm{kK}^{20}$ obtained from the calculations. As the magnitude of this energy gap is a determining factor for the ICT reaction of aminobenzonitriles (PICT model), ${ }^{1,2,6-9}$ this difference may explain why the calculations find that the ICT reaction of NTC6 should be very efficient already in the gas phase, with strongly negative enthalpies $\Delta H$ for the LE $\rightarrow$ ICT reaction, to be discussed in the next section.

LE $\rightarrow$ ICT Enthalpy Difference $\Delta H$. NTC6. From the spectra of NTC6 in the gas phase (Figure 2b), the LE $\rightarrow$ ICT reaction enthalpy is estimated to be slightly positive: $\Delta H=5 \mathrm{~kJ} / \mathrm{mol}$ (Figure 8 and Table 3). In the calculations, in contrast, large negative values, $-19 \mathrm{~kJ} / \mathrm{mol}^{22}$ and $-16 \mathrm{~kJ} / \mathrm{mol}^{20}$ are obtained for the $\Delta H$ between the LE and the TICT state and a positive $\Delta H(25 \mathrm{~kJ} / \mathrm{mol})^{20}$ is found for the LE $\rightarrow$ PICT reaction. Both computations hence predict a very efficient ICT reaction for NTC6 already in the gas phase, contrary to our experimental observation with only a small $\Phi^{\prime}(\mathrm{ICT}) / \Phi(\mathrm{LE})$ ratio of 0.44 (Figure $2 b$ and Table 1). The authors of ref 22 mention that CC2 tends to overestimate the stabilization of the ICT state by about $20 \mathrm{~kJ} / \mathrm{mol}$ and hence estimate that LE and ICT have about the same energy in the gas phase, in better agreement with experiment.

NMC6. With NMC6, for which ICT even does not occur in strongly polar solvents such as $\mathrm{MeCN},{ }^{1,3}$ a large positive gas phase $\Delta H(10.6 \mathrm{~kJ} / \mathrm{mol})$ is computed $(\mathrm{CC} 2)$ for the ICT reaction in ref 22 , corrected to about $31 \mathrm{~kJ} / \mathrm{mol}$ as described above. Considerably larger positive values are obtained in ref 20: 44
$\mathrm{kJ} / \mathrm{mol}$ (TICT) and $28 \mathrm{~kJ} / \mathrm{mol}$ (PICT). It is of interest to note that in ref 20 the PICT state of NMC6 has a lower energy than the TICT state, see ref 49.

DMABN. The small positive experimental $\Delta H$ of $4.5 \mathrm{~kJ} / \mathrm{mol}$ for the LE $\rightarrow$ ICT reaction of DMABN in the gas phase is in accordance with the absence of ICT. That the energy difference between the LE and ICT states of DMABN in the gas phase and also in $n$-hexane is indeed small is supported by the observation that ICT just starts to appear in slightly polar solvents such as DEE. ${ }^{37}$ The experimental gas phase $\Delta H$ is about the same as the computed $\Delta H=1.7 \mathrm{~kJ} / \mathrm{mol}$ (TICT) of ref 20 . A positive $\Delta H$ of about $13 \mathrm{~kJ} / \mathrm{mol}$ is obtained in ref 22, after correction (similar to that employed for NTC6 and NMC6) of the $\mathrm{CC} 2$ result of $-7.7 \mathrm{~kJ} / \mathrm{mol}$. The calculations of ref 19 , however, find a strongly negative $\Delta H$ for DMABN in the gas phase of $-41.4 \mathrm{~kJ} / \mathrm{mol}$ (MRMP2, LE at LE geometry, ICT at ICT geometry), in conflict with experiment.

$E(I C T), E\left(\right.$ FC, ICT), and $\tilde{v}^{\max }(\mathrm{ICT})$ of NTC6 and DMABN. For NTC6 in the gas phase (Figure 8 and Table 3), the experimental energy $E(\mathrm{ICT})(32.2 \mathrm{kK})$ is identical to the calculated energy for the PICT state $(32.17 \mathrm{kK}),{ }^{20}$ but much larger than that for the TICT state: $(28.8 \mathrm{kK})^{20}$ and $(29.9 \mathrm{kK}) .^{22}$ Both computations apparently overstabilize the TICT states (see above). The calculated Franck-Condon energies $E$ (FC,ICT) for NTC6 $(116 \mathrm{~kJ} / \mathrm{mol})^{22}$ and DMABN $(152 \mathrm{~kJ} / \mathrm{mol}),{ }^{22}$ see Figure 5 , are also much larger than the gas phase experimental values of 43.5 and $47.4 \mathrm{~kJ} / \mathrm{mol}$ (Table 3 ).

The gas phase ICT emission maxima $\tilde{v}^{\max }$ (ICT) of NTC6 $(28.56 \mathrm{kK})$ and DMABN $(28.63 \mathrm{kK})$ are both at substantially higher energies than the calculated ${ }^{22}$ maxima of $20.24 \mathrm{kK}$ for NTC6 and 20.08 kK for DMABN (Table 3, Figures 7 and 8). This is the reason why the experimental energy of the ICT Franck-Condon state $E(\mathrm{FC}, \mathrm{ICT})$, calculated via eq 5, is much smaller than the computed energy. The large difference in $E(\mathrm{FC}, \mathrm{ICT})$ could indicate that the molecular structure of the ICT state calculated ${ }^{22}$ for NTC6 and DMABN is substantially different from the experimental ICT structure investigated in the experiments.

Nonplanar Phenyl Ring of Calculated ICT State for DMABN and NTC6. In the calculated ICT state structure of NTC6 and DMABN, ${ }^{20,22}$ the phenyl ring has lost its planarity. The phenyl atom $\mathrm{C}(9)$, to which the amino nitrogen $\mathrm{N}(1)$ of NTC6 is attached (Chart 1), has become pyramidal, which was assumed to lead to additional flexibility of the phenyl ring, making the TICT state of NTC6, NMC6, and also DMABN, energetically accessible from the planar LE. ${ }^{20-22} \mathrm{~A}$ similar distortion of the phenyl ring planarity has been computed for the ICT state of fluorazene, ${ }^{53}$ whereas in another calculation ${ }^{54}$ of this molecule a planar ICT state was reported. Such a nonaromatic distorted phenyl structure for the ICT state is, however, in conflict with the observation that the transient Raman bands of the DMABN ICT state strongly resemble those in the IR spectrum of the benzonitrile radical anion. ${ }^{55,56}$ From the ESR spectrum of this ion, it is seen that all atoms of the phenyl ring are part of a fully conjugated, effectively planar, ${ }^{57}$ aromatic system. ${ }^{58}$ The conclusion can therefore be made that the ICT states in the calculations of refs 20-22 do not have

(53) Xu, X.; Cao, Z.; Zhang, X. J. Phvs. Chem. A 2006, 110, 1740.

(54) He, R.-X.; Li, X.-Y. Chem. Phys. 2007, 332, 325.

(55) Kwok, W. M.; Ma, C.; Matousek, P.; Parker, A. W.; Phillips, D.; Toner, W. T.; Towrie, M.; Umpathy, S. J. Phys. Chem. A 2001, 105, 984.

(56) Juchnovski, I.; Tsvetanov, C.; Panayotov, I. Monatsh. Chem. 1969, $100,1980$. 
the molecular structure of the states from which the ICT fluorescence originates. ${ }^{59,60}$

It has, however, rather ambiguously also been concluded in ref 22 that the ICT state of NTC6 with a planar, nonpyramidal C9 atom was, in fact, the state being the most stable in solution (even in $n$-hexane), due to its slightly larger dipole moment than the other pyramidal ICT states (14.7 D as compared with 11.7-13.5 D). As the shape of the ICT fluorescence band of NTC6 in the vapor phase is similar to that in solution, its maximum correlating well with those in a series of solvents (Figure 3), there is no experimental evidence for a change in molecular structure of the phenyl ring of NTC6 when going from the gas phase to solution. The distorted nonplanar ICT structure from the NTC6 calculations has nevertheless been used in recent publications as an argument against the PICT model. ${ }^{61-63}$

$S_{0}$, LE, and ICT Dipole Moments of NTC6, NMC6, and DMABN. Comparison of Calculated and Experimental Results. Whereas the calculated (i.e., gas phase) ground-state dipole moments $\mu_{\mathrm{g}}\left(\mathrm{S}_{0}\right)$ of NTC6, NMC6, and DMABN are either somewhat (less than $1 \mathrm{D}$ ) smaller ${ }^{20}$ or larger $^{22}$ than the experimental (solution) data of $6.8,6.8$, and $6.6 \mathrm{D}$ (Table 4), ${ }^{1,3,64}$ substantial differences occur between the computed and experimental $\mu_{\mathrm{e}}(\mathrm{LE})$ and, in particular, $\mu_{\mathrm{e}}(\mathrm{ICT})$ dipole moments.

For $\mu_{\mathrm{e}}(\mathrm{LE})$, much smaller values are calculated in refs 19-21 than the experimental $\mu_{\mathrm{e}}(\mathrm{LE})$ of $11 \mathrm{D}$ (NTC6), ${ }^{1} 10.6 \mathrm{D}$ (NMC6) ${ }^{1}$ and $9 \mathrm{D}(\mathrm{DMABN}):^{3} 7.0,6.8$, and $7.1 \mathrm{D}$ (ref 19); 6.0, 6.0, and 6.1 D (refs 20 and 21), see Table 4. From the computations in ref 22, in contrast, larger LE dipole moments for NTC6 (12.6 D) and DMABN (10.1 D) and a similar $\mu_{\mathrm{e}}(\mathrm{LE})$ for NMC6 (10.4 D) are obtained (Table 4), as compared with the experimental $\mu_{\mathrm{e}}(\mathrm{LE})$, the opposite of the two other calculations.

For $\mu_{\mathrm{e}}(\mathrm{ICT})$, the results of the three computational approaches ${ }^{19-23}$ do not show the same differences among each other as found for $\mu_{\mathrm{e}}(\mathrm{LE})$ (Table 4). The calculated data for $\mu_{\mathrm{e}}(\mathrm{ICT})$, with values of $13 \pm 1 \mathrm{D}$, are all considerably smaller than the experimental values of $18 \mathrm{D}$ (Figure 3, Table 4) for NTC6 and $17 \mathrm{D}^{3}$ for DMABN. In ref 22, somewhat surprisingly, $\mu_{\mathrm{e}}(\mathrm{LE})$ is with $12.6 \mathrm{D}$ only slightly smaller than $\left.\mu_{\mathrm{e}} \mathrm{ICT}\right)$ of $13.5 \mathrm{D}$. It is further seen that the dipole moments calculated in ref 20 for the PICT state of NTC6, NMC6, and DMABN are all about $1 \mathrm{D}$ larger than $\mu_{\mathrm{e}}$ (TICT), see Table 4. This is different from other computations, which generally find considerably smaller dipole moments for the PICT than for the TICT state. ${ }^{65}$ To be able to evaluate the differences between the calculated and experimental data, dipole moments in the vapor phase and in solution are therefore needed. They will be discussed

(57) ESR cannot distinguish between a strictly planar (single minimum) benzene radical anion and one with a double minimum undergoing rapid (>10 GHz) population exchange leading to coalescing signals. This does not, however, affect our interpretation that all six C-atoms of the phenyl ring are part of a fully conjugated ring, different from the structure with a pyramidal $\mathrm{C}(9)$ atom obtained from the calculations in refs $20-22$.

(58) Carrington, A.; Todd, P. F. Mol. Phvs. 1963, 6, 161

(59) Zachariasse, K. A.; Druzhinin, S. I.; Mayer, P.; Kovalenko, S. A.; Senyushkina, T. Chem. Phvs. Lett. 2009, 484, 28.

(60) Zachariasse, K. A.; Druzhinin, S. I.; Kovalenko, S. A.; Senyushkina, T. J. Chem. Phvs. 2009, 131, 224313.

(61) Pigliucci, A.; Vauthey, E.; Rettig, W. Chem. Phys. Lett. 2009, 469, 115.

(62) Lee, J.-K.; Fujiwara, T.; Kofron, W. G.; Zgierski, M. Z.; Lim, E. C. J. Chem. Phvs. 2008, 128, 164512.

(63) Zgierski, M. Z.; Fujiwara, T.; Lim, E. C. Chem. Phys. Lett. 2008 $463,289$.

(64) Baumann, W.; Bischof, H.; Fröhling, J.-C.; Brittinger, C.; Rettig, W.; Rotkiewicz, K. J. Photochem. Photobiol., A 1992, 64, 49.

(65) Zilberg, S.; Haas, Y. J. Phys. Chem. A 2002, 106, 1.
Table 4. Experimental and Calculated Dipole Moments ${ }^{a}$ (in Debye) for the $S_{0}$, LE and ICT states of NTC6, NMC6, and DMABN

\begin{tabular}{|c|c|c|c|}
\hline & NTC6 & NMC6 & DMABN \\
\hline$\mu_{\mathrm{g}}\left(\mathrm{S}_{0}\right)^{\text {exp }}$, refs $1,3,64$ & $6.8^{b}$ & $6.8^{b}$ & 6.6 \\
\hline$\mu_{\mathrm{g}}\left(\mathrm{S}_{0}\right)^{\text {calc }}$, ref 19 & & & 6.2 \\
\hline$\mu_{\mathrm{g}}\left(\mathrm{S}_{0}\right)^{\text {calc }}$, ref 20 & 6.1 & 6.1 & 6.1 \\
\hline$\mu_{\mathrm{g}}\left(\mathrm{S}_{0}\right)^{\text {calc }}$, ref 22 & 7.7 & 7.5 & 7.4 \\
\hline$\mu_{\mathrm{e}}(\mathrm{LE})^{\exp }$, ref 1,3 & $(11)^{c}$ & 10.6 & 9 \\
\hline$\mu_{\mathrm{e}}(\mathrm{LE})^{\text {calc }}$, ref 19 & $(7.0)^{d}$ & $(6.8)^{d}$ & $(7.1)^{d}$ \\
\hline$\mu_{\mathrm{e}}(\mathrm{LE})^{\mathrm{calc}}$, ref 20 & 6.0 & 6.0 & 6.1 \\
\hline$\mu_{\mathrm{e}}(\mathrm{LE})^{\mathrm{calc}}$, ref 22 & 12.6 & 10.4 & 10.1 \\
\hline$\mu_{\mathrm{e}}(\mathrm{ICT})^{\exp }$, Figure 3 , ref 3 & 18 & & \\
\hline$\mu_{\mathrm{e}}(\mathrm{ICT})^{\text {calc }}$, ref 19 & $(13.9)^{e}$ & $(13.2)^{e}$ & $(13.2)^{e}$ \\
\hline \multirow[t]{2}{*}{$\mu_{\mathrm{e}}(\mathrm{ICT})^{\text {calc } f}$, ref 20} & 13.0 (TICT) & 12.1 (TICT) & 13.5 (TICT) \\
\hline & 13.8 (PICT) & 13.4 (PICT) & 13.8 (PICT) \\
\hline$\mu_{\mathrm{e}}(\mathrm{ICT})^{\text {calc }}$, ref 22 & 13.5 & 12.7 & 13.3 \\
\hline
\end{tabular}

${ }^{a}$ The experimental dipole moments are for the molecules in solution, whereas the computed dipole moments refer to the gas phase $\mathrm{e}^{20,22}$ or to a nonpolar (alkane) solvent. ${ }^{19}{ }^{b}$ From calculated (AM1) dipole moments $\mu_{\mathrm{g}}$, scaled by $\mu_{\mathrm{g}}=6.6 \mathrm{D}$ for DMABN. ${ }^{1}{ }^{c}$ Dipole moment uncertain because of strongly decreasing relative intensity of the LE emission overlapping with predominant ICT fluorescence when the solvent polarity becomes larger. ${ }^{1}{ }^{d}$ The data, in a nonpolar (alkane) solvent, do not refer to the LE state, but to the $S_{1}$ state (Figure 5) at the $\mathrm{S}_{0}$-optimized geometry. For $\mu_{\mathrm{e}}(\mathrm{LE})$ of DMABN, $\sim 4 \mathrm{D}$ is calculated, see ref $19 .{ }^{e}$ The data, in a nonpolar (alkane) solvent, do not refer to the ICT state, but to the $\mathrm{S}_{2}$ state (Figure 5) at the $\mathrm{S}_{0}$-optimized geometry. For $\mu_{\mathrm{e}}$ (ICT) $\sim 15 \mathrm{D}$ is calculated, see ref $19 .{ }^{f}$ Twisted (TICT) and Planar (PICT) ICT states.

in the next section. It is important to note that the theoretical $\mu$ data of refs 20 and 22 refer to the gas phase and those of ref 19 are for a nonpolar solvent, whereas the experimental dipole moments are determined from solvatochromic measurements in solution. The dipole moments $\mu_{\mathrm{e}}(\mathrm{LE})$ and $\mu_{\mathrm{e}}(\mathrm{ICT})$ of NTC6, NMC6, and DMABN calculated in ref 19 for a nonpolar solution $(13.9,13.2$, and 13,2 D, Table 4), are nevertheless practically the same as those computed ${ }^{20,22}$ for the gas phase (13 $\left.\pm 1 \mathrm{D}\right)$.

Experimental Excited-State Dipole Moments in Solution. Excited-state dipole moments $\mu_{\mathrm{e}}$ of molecules in solution can be determined from solvatochromic measurements, ${ }^{37,64}$ electrooptical experiments, ${ }^{64}$ or time-resolved microwave conductivity $(\text { TRMC })^{3}$ data. $^{66}$

In the solvatochromic method, the dipole moment $\mu_{\mathrm{e}}$ is assumed to be constant, independent of solvent polarity and polarizability, a possibly intrinsic deficiency of the method. ${ }^{37,64,66,67}$ On the basis of the large polarizability of the LE and ICT states of molecules such as DMABN and NTC6, there are reasons to assume,${ }^{64}$ however, that this assumption is too simple and that $\mu_{\mathrm{e}}$ will become larger with increasing solvent polarity and polarizability. This, then, would mean that (at least) the solvatochromic $\mu_{\mathrm{e}}$ data (with constant $\mu_{\mathrm{e}}$ ) reported in the literature are average values, with a magnitude depending on the solvent polarity range covered by the measurements. In contrast with this expectation, an inspection of TRMC data for $\mu_{\mathrm{e}}(\mathrm{LE})$ of $\mathrm{ABN}, \mathrm{DMABN}$ and derivatives indicates that these data do in fact not depend of solvent polarity when going from cyclohexane $\left(\varepsilon^{25}=2.02\right)$ to $p$-dioxane with an effective dielectric constant ${ }^{3,37}$ of around $7 .^{3}$ A similar conclusion is made for $\mu_{\mathrm{e}}$ (ICT) of DMABN and several other 4-(dialkylamino)benzonitriles. $^{3}$

(66) Suppan, P.; Ghoneim, N. Solvatochromism, The Royal Society of Chemistry: Cambridge, U.K., 1997.

(67) Liptay, W. In Excited States; Lim, E. C., Ed.; Academic Press: New York, 1974; Vol. 1, p 129. 
Different from these TRMC results, it appears from electrooptical emission (EOEM) experiments that $\mu_{\mathrm{e}}$ (ICT) of MMD becomes larger with increasing solvent polarity, from $11.7 \mathrm{D}$ in the vapor phase via $12.3 \mathrm{D}$ in $n$-hexane $\left(\varepsilon^{25}=1.88\right)$ to 14.5 $\mathrm{D}$ in $p$-dioxane $\left(\varepsilon^{25}{ }_{\text {eff }} \sim 7\right),{ }^{64}$ with a saturation effect in solvents more polar than $\operatorname{di}\left(n\right.$-pentyl) ether ${ }^{37}\left(\varepsilon^{25}=2.73\right)$. For the $\mu_{\mathrm{e}}(\mathrm{LE})$ of NEC5, also a small, but possibly significant, increase with solvent polarity was found from EOEM measurements: $5.7 \mathrm{D}$ (cyclohexane), 6.2 D ( $p$-dioxane) and 6.4 D (fluorobenzene, $\varepsilon^{25}$ $=5.34) .{ }^{64}$ Note that the $\mu_{\mathrm{e}}(\mathrm{LE})$ dipole moment determined by EOEM are much smaller than those coming from solvatochromic experiments: $5.8 \mathrm{D}$ as compared with $9 \mathrm{D}$ for DMABN. ${ }^{37,64}$

An experimental indication that the ICT dipole moment increases when the solvent polarity becomes larger, may come from our thermochromic measurements with DMABN, $N$-(4cyanophenyl)pyrrole (PP4C), and $N$-(3-cyanophenyl)pyrrole (PP3C), from which it follows that between DEE and MeCN $\mu_{\mathrm{e}}(\mathrm{ICT})$ increases from 16.9 to $32.7 \mathrm{D}$ (DMABN), 15.0 to 29.8 $\mathrm{D}$ (PP4C) and 14.8 to $29.4 \mathrm{D}$ (PP3C). ${ }^{37}$ From the observation that $\mu_{\mathrm{e}}$ (ICT) remains practically constant in the three polar solvents $\mathrm{MeCN}\left(\varepsilon^{25}=36.1\right)$, ethyl cyanide $\left(\varepsilon^{25}=28.3\right)$, and $n$-propyl cyanide $\left(\varepsilon^{25}=24.2\right)$, it was concluded that this dipole moment does not depend on solvent polarity. ${ }^{37}$ It may also mean that a saturation effect appears in polar solvents, similar to what was presented above for MMD. ${ }^{64}$

Gas Phase Dipole Moments. For an evaluation of the calculated dipole moments, ${ }^{20-22}$ vapor phase data would be required. Such gas phase dipole moments cannot be directly deduced from solvatochromic or TRMC measurements, as a constant dipole moment (independent of solvent polarity and polarizability) is assumed in these methods, as mentioned above, but they can be determined by electro-optical or Stark effect measurements. The (scarce) experimental vapor phase dipole moments will be reviewed here, for 4-aminobenzonitrile (ABN) and aniline.

4-Aminobenzonitrile (ABN). The dipole moment of the $\mathrm{S}_{0}$ and $S_{1}(\mathrm{LE})$ states of $A B N$ in the vapor phase have been determined via Stark effect experiments: $\mu_{\mathrm{g}}\left(\mathrm{S}_{0}\right)=6.41 \mathrm{D}$ and $\mu_{\mathrm{e}}(\mathrm{LE})=7.20 \mathrm{D}^{68}{ }^{68}$ From TRMC measurements in solution, a larger average dipole moment $\mu_{\mathrm{e}}(\mathrm{LE})$ of $8.3 \mathrm{D}$ is determined for $\mathrm{ABN}$ : cyclohexane $(8.0 \mathrm{D})$, benzene $(8.5 \mathrm{D})$ and $p$-dioxane (8.3 D), with $\mu_{\mathrm{g}}\left(\mathrm{S}_{0}\right)=6.6 \mathrm{D}$. $^{3}$ Solvatochromic studies similarly resulted in $\mu_{\mathrm{e}}(\mathrm{LE})=8.4$ D. ${ }^{69}$ The computed, i.e. gas phase, values for $\mu_{\mathrm{e}}(\mathrm{LE})$ of $\mathrm{ABN}$ are $5.65 \mathrm{D},{ }^{68} 5.3 \mathrm{D}(\mathrm{LE}, \mathrm{FC})^{20}$ and $6.0 \mathrm{D}\left(\mathrm{S}_{1}, 1 \mathrm{~B}_{2}\right) .{ }^{65}$ It hence follows that the vapor phase $\mu_{\mathrm{e}}(\mathrm{LE})$ of $\mathrm{ABN}(7.2 \mathrm{D})$ is about $1 \mathrm{D}$ smaller than the solution value of $8.3 \mathrm{D}$, whereas the calculated $\mu_{\mathrm{e}}(\mathrm{LE})$ of $\mathrm{ABN}$ are still smaller: $5.5 \pm 0.15 \mathrm{D}$ as compared with 7.2 D (gas phase), a difference of about $24 \%$.

Aniline. The excited-state dipole moment $\mu_{\mathrm{e}}\left(\mathrm{S}_{1}\right)$ of the $\mathrm{S}_{1}$ state of aniline, comparable to $\mu_{\mathrm{e}}(\mathrm{LE})$ of $\mathrm{ABN}$, has been determined by solvatochromy ${ }^{69,70}$ from the fluorescence spectra in solution $\left(5.0 \mathrm{D}^{69}\right.$ and $\left.5.8 \mathrm{D}^{70}\right)$, as well as by Stark effect experiments ${ }^{71}$ in the gas phase $(2.45 \mathrm{D})$. The large difference between these two results has been explained by field-induced mixing of the nearby $\mathrm{S}_{1}\left(\mu_{\mathrm{e}}=2.45 \mathrm{D}\right)$ and $\mathrm{S}_{2}\left(\mu_{\mathrm{e}}=6.0 \mathrm{D}\right)$ electronic states of aniline in solution. ${ }^{68,71}$ From measurements of the Stark effect on the rotationally resolved $\mathrm{S}_{1} \leftarrow \mathrm{S}_{0}$ fluorescence excitation

(68) Borst, D. R.; Korter, T. M.; Pratt, D. W. Chem. Phys. Lett. 2001, 350,485

(69) Jiang, S.; Levy, D. H. J. Phys. Chem. A 2003, 107, 6785.

(70) Noukakis, D.; Suppan, P. Spectrochim. Acta 1987, 43A, 1317.

(71) Lombardi, J. R. J. Phys. Chem. A 1998, 102, 2817. spectrum of aniline, $\mu_{\mathrm{e}}\left(\mathrm{S}_{1}\right)=2.8 \mathrm{D}$ and $\mu_{\mathrm{g}}\left(\mathrm{S}_{0}\right)=1.1 \mathrm{D}$ have been determined, whereas from calculations, $\mu_{\mathrm{e}}\left(\mathrm{S}_{1}\right)=2.87 \mathrm{D}$ (CIS) and $\mu_{\mathrm{g}}\left(\mathrm{S}_{0}\right)=0.97 \mathrm{D}(\mathrm{MP} 2)$ were found. ${ }^{68,72}$

Calculated versus Solution Dipole Moments. DMABN, MMD, NTC6 and NMC6. Although it is to be expected (see above) that the transition from the gas phase to solution will lead to larger dipole moments, an average increase when going from calculations (i.e., gas phase) to solution of $\Delta \mu$ of $5.5 \mathrm{D}$ for NTC6 and 3.6 D for DMABN (Table 4) seems to be very large. Experimental data are scarce, but exist for MMD, showing ICT emission in the vapor phase, with $\mu_{\mathrm{e}}(\mathrm{ICT})=12.3 \mathrm{D}$ in $n$-heptane and 14.5 D in $p$-dioxane, both dipole moments larger than in the gas phase $(11.8 \mathrm{D}) .{ }^{64}$ Although the problem of induced dipole moments should be considered in this connection, ${ }^{66,67}$ these results could indicate that the computed dipole moments for the ICT states of NTC6, NMC6, and DMABN $(13 \pm 1 \mathrm{D})$ are in fact too small as compared with the experimental values of $18 \mathrm{D}$ (NTC6) and $17 \mathrm{D}$ (DMABN), see Table 4. Note in this connection that the dipole moments $\mu_{\mathrm{e}}(\mathrm{LE})$ and $\mu_{\mathrm{e}}$ (ICT) of NTC6, NMC6, and DMABN calculated in ref 19 for a nonpolar (alkane) solution $(13.9,13.2$, and $13.2 \mathrm{D}$, Table 4) are, as mentioned above, practically the same as those computed $^{20,22}$ for the gas phase $(13 \pm 1 \mathrm{D})$. It is further somewhat surprising that the calculated $\mu_{\mathrm{e}}(\mathrm{LE})$ of NTC6 in ref 22 is $15 \%$ larger than the experimental value, whereas the computed $\mu_{\mathrm{e}}$ (ICT) is $71 \%$ smaller. In the case of DMABN (Table 4) a similar discrepancy exists, which may point to the desirability of further computational efforts.

\section{Conclusions}

In the vapor phase fluorescence spectra of NTC6 and DIABN, a dual emission from a LE and an ICT state is observed. In contrast, a LE $\rightarrow$ ICT reaction does not take place with DMABN and NMC6 in the gas phase, for which only LE emission is found. In the solvatochromic plot of the $\tilde{v}^{\max }$ (ICT) of NTC6 against those of DIABN, the vapor maximum is located on the same line as those of the entire solvent series from $\mathrm{pFMCH}$ to $\mathrm{MeCN}$, resulting in a dipole moment $\mu_{\mathrm{e}}(\mathrm{ICT})$ of $18 \mathrm{D}$ for all media, irrespective of solvent polarity. The spectral information obtained in the vapor phase is employed to make a comparison between the results of computations ${ }^{19,20,22}$ on NTC6, NMC6, and DMABN and experimental data of these molecules in the ground state $\mathrm{S}_{0}$ and the excited states $\mathrm{S}_{1}, \mathrm{~S}_{2}, \mathrm{LE}$, and ICT.

From crystal structures of NTC6, NMC6, and a number of analogues, the twist angle $\theta$, the pyramidal angle $\varphi$, and also phenyl and alicyclic bond lengths are compared with calculations of $\mathrm{S}_{0}$. The experimental amino twist angle $\theta$ is small for NMC6 $\left(3.3^{\circ}\right)$ and NEC6 $\left(4.6^{\circ}\right)$ and then becomes larger for NIC6 $\left(9.5^{\circ}\right)$ and NTC6 $\left(22.7^{\circ}\right)$, due to the increasing bulkiness of the $N$-alkyl group. The amino group is practically not twisted for the NXC5 compounds: NMC5 $\left(2.7^{\circ}\right)$, NEC5 $\left(1.1^{\circ}\right)$, and NIC5 $\left(1.4^{\circ}\right)$. The calculated angles $\theta$ for NMC6 are $19.6^{\circ},{ }^{19} 0^{\circ},{ }^{20}$ and $0.1^{\circ},{ }^{22}$ only the last two values being close to the experimental (crystal) angle of $3.3^{\circ}$. For NTC6, the calculations of $\theta$ find $32.1^{\circ},{ }^{19}$ $32.5^{\circ},{ }^{20}$ and $26.8^{\circ},{ }^{22}$ clearly larger than the experimental $\theta$ of $22.7^{\circ}$. For NMC6 to NTC6, the increase in bulkiness of the $N$-alkyl group leads to a substantial lengthening of the $N-$ C(alkyl) bond, from $144.4 \mathrm{pm}$ for NMC6 to $149.3 \mathrm{pm}$ for NTC6, in accordance with the calculations. The computed pyramidal angles $\varphi$ of NTC6 are $19.5^{\circ},{ }^{19} 3.2^{\circ},{ }^{20}$ and $18.9^{\circ} .^{22}$

(72) Korter, T. M.; Borst, D. R.; Butler, C. J.; Pratt, D. W. J. Am. Chem. Soc. 2001, 123, 96. 
The angles $\varphi$ of refs 19 and 22 are about double the experimental value of $9.6^{\circ}$, whereas the value from ref 20 is considerably smaller. The calculated amino pyramidal angles $\varphi$ for NMC6 are $26.3^{\circ},{ }^{19} 28.7^{\circ},{ }^{20}$ and $24.8^{\circ}, 22$ all nearly the double of the experimental angle of $15.5^{\circ}$. It hence follows that substantial differences exist between the experimental (crystal) and calculated $\mathrm{S}_{0}$ structures.

The differences between the experimental gas phase results and the calculations for NTC6, NMC6, and DMABN are mainly concerned with the LE $\rightarrow$ ICT energetics and the dipole $\mu_{\mathrm{e}}$ (ICT) of the ICT state. As compared with the experimental LE fluorescence maximum $\tilde{v}^{\max }(\mathrm{LE})=29.67 \mathrm{kK}$ of DMABN, 30.49 $\mathrm{kK}^{22}$ and $29.69 \mathrm{kK}^{19}$ are calculated, whereas for NMC6 the experimental $\tilde{v}^{\max }(\mathrm{LE})$ of $29.14 \mathrm{kK}$ is likewise similar to the theoretical $29.60 \mathrm{kK} .{ }^{22}$ Such a good agreement between computed and experimental results is not obtained for $\tilde{v}^{\max }$ (ICT), with $20.08 \mathrm{kK}^{22}$ much smaller than the $28.63 \mathrm{kK}$ estimated for DMABN in the vapor phase. For NTC6, the calculated ${ }^{22}$ $\tilde{v}^{\max }(\mathrm{LE})=26.94 \mathrm{kK}$ and $\tilde{v}^{\max }(\mathrm{ICT})=20.24 \mathrm{kK}$ are considerably smaller than the experimental values of $29.18 \mathrm{kK}$ (LE) and $28.56 \mathrm{kK}$ (ICT).

From the LE/ICT energy diagrams for DMABN, NTC6, and NMC6, which contain the energies of the $S_{1}$ and $S_{2}$ FC-states (absorption spectra) and of the LE and ICT states, the following results are obtained from a comparison between experimental and computational data. For DMABN, the calculated energies $E\left(\mathrm{~S}_{1}\right)$ in ref $20(34.66 \mathrm{kK})$ and ref $22(35.57 \mathrm{kK})$ are larger than the experimental value of $33.31 \mathrm{kK}$, whereas a smaller energy is obtained in ref $19(31.32 \mathrm{kK})$. The same condition is found for $E\left(\mathrm{~S}_{2}\right): 36.83 \mathrm{kK}$ (vapor), as compared with $37.18 \mathrm{kK}$ (ref 20), $38.47 \mathrm{kK}$ (ref 22), $34.63 \mathrm{kK}$ (ref 19). The calculated energy gap $\triangle E\left(\mathrm{~S}_{1}, \mathrm{~S}_{2}\right)$ of DMABN is smaller than the experimental result of $3.52 \mathrm{kK}: 3.31 \mathrm{kK},{ }^{19} 2.90 \mathrm{kK},{ }^{22}$ and $2.52 \mathrm{kK} .{ }^{20}$ A similar situation is encountered with the $\Delta E\left(\mathrm{~S}_{1}, \mathrm{~S}_{2}\right)$ of NMC6: $2.98 \mathrm{kK}$ (experimental), $2.34 \mathrm{kK}^{20}$ and $2.18 \mathrm{kK} .^{22}$ A much larger discrepancy is found for NTC6: $\Delta E\left(\mathrm{~S}_{1}, \mathrm{~S}_{2}\right)=2.37 \mathrm{kK}$ (experimental) as compared with only $0.81 \mathrm{kK}^{22}$ and $-0.24 \mathrm{kK} .{ }^{20}$ Note that for NTC6 in the calculations of ref 20 the order of $S_{1}$ and $\mathrm{S}_{2}$ as present in DMABN and NMC6 has been reversed, which is not supported by the vapor phase experiments.

For an ICT reaction, $\Delta H$ (the difference between the energies $E(\mathrm{LE})$ and $E(\mathrm{ICT})$ ) obviously is an essential issue. For DMABN, the experimental $\Delta H$ equals $4.5 \mathrm{~kJ} / \mathrm{mol}$, whereas $1.7 \mathrm{~kJ} / \mathrm{mol}$ (TICT) and $29.7 \mathrm{~kJ} / \mathrm{mol}$ (PICT) are computed in ref $20 \mathrm{in}$ accordance with the absence of an ICT reaction in the gas phase. $\Delta H$ is negative, however, for DMABN in ref $22(-7.7 \mathrm{~kJ} / \mathrm{mol})$ and ref $19(-41.4 \mathrm{~kJ} / \mathrm{mol})$, which would predict an effective LE $\rightarrow$ ICT reaction, contrary to the vapor phase observation. With NTC6, strongly negative $\Delta H$ values are calculated, -15.9 $\mathrm{kJ} / \mathrm{mol}^{20}$ and $-19.3 \mathrm{~kJ} / \mathrm{mol},{ }^{20}$ substantially different from the experimental $\Delta H$ of $5.0 \mathrm{~kJ} / \mathrm{mol}$.

For NTC6, the computed ground-state dipole moment $\mu_{\mathrm{g}}\left(\mathrm{S}_{0}\right)$ is with $6.1 \mathrm{D}^{20}$ somewhat smaller than the experimental value $(6.6 \mathrm{D})$, whereas in ref 22 a clearly larger $\mu_{\mathrm{g}}\left(\mathrm{S}_{0}\right)=7.7 \mathrm{D}$ is obtained. Similar results are found for DMABN and NMC6. The calculated $\mu_{\mathrm{e}}(\mathrm{LE})$ in ref $19(\sim 7 \mathrm{D})$ and ref $20(\sim 6 \mathrm{D})$ are likewise considerably smaller that the experimental $9 \mathrm{D}$ (DMABN) and $11 \mathrm{D}$ (NTC6 and NMC6), whereas in ref 22 a larger $\mu_{\mathrm{e}}(\mathrm{LE})$ is computed for NTC6 (12.6 D) and DMABN (10.1 D), but with a value comparable to that of the experiment results for NMC6 (10.4 D). The calculated ICT dipole moments $\mu_{\mathrm{e}}(\mathrm{ICT})$ for NTC6 and DMABN of around $13 \mathrm{D}$ are much smaller than the experimental results of 18 D (NTC6) and 17 $\mathrm{D}$ (DMABN). This may indicate that the molecular ICT structure derived from the computations is not the same as that encountered in the experiments. Support for this interpretation that the calculated ICT state of NTC6, NMC6, and DMABN with a nonplanar phenyl group (in which the resonance in the phenyl ring is interrupted) is in conflict with experimental structure comes from the ICT excited-state absorption (ESA) spectra of these molecules. These ESA spectra resemble the absorption spectrum of the benzonitrile radical anion, with all six phenyl carbons in full resonance.

Acknowledgment. Many thanks are due to Dr. A. Köhn (Mainz), Dr. I. Gómez (Tarragona), and Prof. M. Reguero (Tarragona) for many clarifying discussions and for providing us with unpublished details of their calculations. We are also thankful to Profs. Y. Amatatsu (Akita), H.-B. Buergi (Bern), A. Domenicano (L'Aquila), Ch. Hättig (Bochum), D. W. Pratt (Pittsburgh), and G. M. Sheldrick (Göttingen) for useful correspondence.

Supporting Information Available: Crystallographic data and fluorescence maxima for NTC6 and DIABN in a series of solvents and in the vapor phase. This material is available free of charge via the Internet at http://pubs.acs.org.

JA101336N 